Cochrane Database of Systematic Reviews

\title{
Surgical interventions for the prevention or treatment of lymphoedema after breast cancer treatment (Review)
}

Markkula SP, Leung N, Allen VB, Furniss D

Markkula SP, Leung N, Allen VB, Furniss D.

Surgical interventions for the prevention or treatment of lymphoedema after breast cancer treatment.

Cochrane Database of Systematic Reviews 2019, Issue 2. Art. No.: CD011433.

DOI: 10.1002/14651858.CD011433.pub2.

www.cochranelibrary.com 
TABLE OF CONTENTS

HEADER 1

ABSTRACT

PLAIN LANGUAGE SUMMARY

SUMMARY OF FINDINGS

BACKGROUND

OBJECTIVES

METHODS

RESULTS

Figure 1.

Figure 2.

Figure 3.

Figure 4.

DISCUSSION

AUTHORS' CONCLUSIONS

ACKNOWLEDGEMENTS

REFERENCES

CHARACTERISTICS OF STUDIES

DATA AND ANALYSES

Analysis 1.1. Comparison 1 Prevention of LE, Outcome 1 Development of LE.

Analysis 2.1. Comparison 2 Treatment of LE, Outcome 1 Reduction of LE.

Analysis 2.2. Comparison 2 Treatment of LE, Outcome 2 Pain score (1-10 scale).

Analysis 2.3. Comparison 2 Treatment of LE, Outcome 3 Heaviness sensation score (1-10 scale).

Analysis 2.4. Comparison 2 Treatment of LE, Outcome 4 Function score (1-10 scale).

Analysis 2.5. Comparison 2 Treatment of LE, Outcome 5 Number of infections per year. APPENDICES

WHAT'S NEW

CONTRIBUTIONS OF AUTHORS

DECLARATIONS OF INTEREST

SOURCES OF SUPPORT

DIFFERENCES BETWEEN PROTOCOL AND REVIEW

INDEX TERMS 
[Intervention Review]

\section{Surgical interventions for the prevention or treatment of lymphoedema after breast cancer treatment}

Silja P Markkula1 ${ }^{\text {, Nelson Leung }}{ }^{2}$, Victoria B Allen ${ }^{3}$, Dominic Furniss ${ }^{4}$

1Department of Plastic Surgery, Helsinki University Hospital, Helsinki, Finland. 2Wessex Deanery, Portsmouth, UK. 3Department of Infection, St. Thomas' Hospital, London, UK. “Botnar Research Centre, NDORMS, Oxford University, Oxford, UK

Contact address: Dominic Furniss, Botnar Research Centre, NDORMS, Oxford University, Windmill Road, Oxford, Oxfordshire, OX3 7HF, UK.dominic.furniss@ndorms.ox.ac.uk.

Editorial group: Cochrane Breast Cancer Group.

Publication status and date: Edited (no change to conclusions), published in Issue 2, 2019.

Citation: Markkula SP, Leung N, Allen VB, Furniss D. Surgical interventions for the prevention or treatment of lymphoedema after breast cancer treatment. Cochrane Database of Systematic Reviews 2019, Issue 2. Art. No.: CD011433. DOI: 10.1002/14651858.CD011433.pub2.

Copyright (c) 2019 The Cochrane Collaboration. Published by John Wiley \& Sons, Ltd.

\section{A B S T R A C T}

\section{Background}

Breast cancer is the most common type of cancer amongst women worldwide, and one distressing complication of breast cancer treatment is breast and upper-limb lymphoedema. There is uncertainty regarding the effectiveness of surgical interventions in both the prevention and management of lymphoedema affecting the arm after breast cancer treatment.

\section{Objectives}

1. To assess and compare the efficacy of surgical interventions for the prevention of the development of lymphoedema (LE) in the arm after breast cancer treatment.

2. To assess and compare the efficacy of surgical interventions for the treatment of established LE in the arm after breast cancer treatment.

\section{Search methods}

We searched the Cochrane Breast Cancer Group's Specialised Register, the Cochrane Central Register of Controlled Trials, MEDLINE, Embase, the Cumulative Index to Nursing and Allied Health Literature (CINAHL), the WHO International Clinical Trials Registry Platform (ICTRP) and ClinicalTrials.gov for all prospectively registered and ongoing trials on 2 November 2017. Reference lists of included studies were also handsearched by three review authors for additional eligible trials.

\section{Selection criteria}

All randomised controlled trials (RCTs) comparing a surgical intervention for the prevention or treatment of lymphoedema of the arm after breast cancer treatment to either standard intervention, placebo intervention, or another surgical intervention were included. Patients of both sexes and all ages who have had treatment for their breast cancer were considered. No limits were applied to language or study location. Three authors independently determined the eligibility of each study.

\section{Data collection and analysis}

Three authors independently extracted data for each included study using a pre-designed data extraction pro forma and used Cochrane's 'risk of bias' tool for assessing risk of bias. Dichotomous variables were analysed using the Mantel-Haenszel method to estimate risk ratios (RRs). Differences in continuous variables were expressed as mean differences (MDs). GRADE was used to assess the certainty of the evidence provided by the included studies. 


\section{Main results}

Two studies involving 95 participants examined surgical interventions for preventing breast cancer-related lymphoedema. Both studies evaluated the efficacy of the lymphaticovenular anastomosis technique as part of a preventative management protocol. Both studies were deemed to be at unclear risk of bias overall. Statistical variation between the studies was low, which increases the reliability of the evidence. However, the two studies were conducted in the same centre. Lymphaticovenular anastomosis appears to result in a reduction in the incidence of lymphoedema compared to nonoperative management with a risk ratio of 0.20 (95\% Cl 0.06 to 0.63 , $\mathrm{P}=0.006$; 95 participants; low-certainty evidence). The RCTs did not evaluate any of the secondary outcomes.

One study involving 36 participants evaluated the effectiveness of vascularised lymph node transfer for treating breast cancer-related lymphoedema. The trial was deemed to be at unclear risk of bias. For participants suffering from stage 2 lymphoedema, the evidence suggested reductions in limb volume (MD $-39.00 \%, 95 \% \mathrm{Cl}-47.37 \%$ to $-30.63 \%$, very low-certainty evidence), pain scores (MD $-4.16,95 \%$ $\mathrm{Cl}-5.17$ to -3.15 , very low-certainty evidence), heaviness sensation (MD $-4.27,95 \% \mathrm{Cl}-5.74$ to -2.80 , very low-certainty evidence), mean number of infections/year ( $\mathrm{MD}-1.22,95 \% \mathrm{Cl}-2.00$ to -0.44 , very low-certainty evidence), and an improvement in overall function scores (MD $-3.77,95 \% \mathrm{Cl}-4.89$ to -2.65 , very low-certainty evidence) for those who had undergone vascularised lymph node transfer compared to those who had undergone no treatment.

\section{Authors' conclusions}

There is low-certainty evidence that lymphaticovenular anastomosis is effective in preventing the development of lymphoedema after breast cancer treatment based on the findings from two studies. One study providing very low-certainty evidence found that vascularised lymph node transfer is an efficacious option in the treatment of established stage 2 lymphoedema related to breast cancer. Important secondary outcomes in this review were rarely reported in the included studies. More high-quality RCTs are required to further elucidate the effectiveness of surgical interventions in the prevention and treatment of lymphoedema after breast cancer treatment. At the time of this review, no ongoing trials on this topic were identified.

\section{PLAIN LANGUAGE SUMMARY}

\section{Surgical techniques for preventing and treating arm swelling from lymphoedema after breast cancer treatment}

\section{What is the issue?}

Many women in the world are affected by breast cancer. Radiotherapy and surgery used for breast cancer treatments target the breast, chest and axilla (or armpit) of the affected side and could damage the local lymphatics of those regions. This results in poor drainage of fluid from the affected arm, which could lead to a sensation of heaviness and visible swelling. A term used to describe this condition is lymphoedema. Lymphoedema is well-recognised by patients and health care professionals. It is uncomfortable and could interfere with many aspects of daily life. In addition, some patients regard their one-sided arm swelling as unsightly. Long-term swelling could also degrade the quality of the skin and lead to recurrent skin infections. Traditional measures to manage this troublesome condition include arm exercises, massage, and compression stockings. While these measures are effective in reducing the arm swelling, they require time, patience, and daily dedication on the patient's part, and can come at a cost to the patient. These traditional measures need to be continued lifelong in order to remain effective.

\section{Study question}

Health care professionals have examined alternative ways to manage lymphoedema after breast cancer treatment. This report reviews the effectiveness of surgical techniques that have been developed to either prevent or treat this condition.

\section{Study results}

A number of techniques have been proposed, but only three studies published by November 2017 met the inclusion criteria for our present review. Two studies looked at preventing lymphoedema and one study looked at treating lymphoedema. In total, these three studies involved 131 individuals.

Two studies focused on the surgical technique of lymphaticovenular anastomosis (a preventive procedure), which joins lymphatic vessels to blood vessels and utilises the circulatory system to drain the excess fluid from the arm. They showed that individuals who undergo this surgical procedure have a reduced risk of developing lymphoedema ( 255 fewer cases of developing lymphoedema per 1000 women, where the true value may be somewhere between 118 fewer to 300 fewer cases developing lymphoedema per 1000 women) compared to those who do not. These two studies did not provide data for important secondary outcomes such as patient-reported outcomes, ability to discontinue further interventions for lymphoedema, surgical complications, or long-term complications.

One study evaluated a vascularised lymph node transfer technique which transferred a piece of tissue containing lymph nodes from the groin or abdomen to the armpit of the limb affected by lymphoedema. The authors observed that those who underwent this procedure experienced reductions in: 
- limb volume: on average, women who underwent the procedure had 39\% reduction in limb volume compared to those who had standard care alone;

- pain: on average, women who had the procedure scored 4.16 points lower on a 10-point scale (i.e. $1=$ no pain, $10=$ extreme pain) than those who had standard care alone;

- heaviness sensation: on average, women who had the procedure scored 4.27 points lower on a 10-point sensation heaviness scale (i.e. 1 = no heaviness sensation, 10 = extreme heaviness sensation) compared to those who had standard care alone; and

- infection: on average, women who had the procedure had 1.22 fewer infections per year compared to those who had standard care alone.

The vascularised lymph node transfer technique also provided a gain in functional improvement meaning that, on average, women who underwent the procedure scored 3.77 points better on the overall function score (function measured on a 10 point scale where $1=$ excellent function, $10=$ very poor function) compared to those who had standard care alone. The study did not provide data for some important secondary outcomes such as the ability to discontinue further interventions for lymphoedema or long-term complications.

\section{Certainty of the evidence}

The certainty of the evidence supporting the use of lymphaticovenular anastomosis in the prevention of lymphoedema was low, consisting of only two small studies from one centre. Similarly, only one single-centre study assessed the use of vascularised lymph node transfer and provided overall very low-certainty evidence supporting the use of the procedure in the treatment of upper limb lymphoedema. 
S U M MARY OF FINDINGS

Summary of findings for the main comparison. Lymphaticovenular anastomosis compared to standard care for prevention of lymphoedema development

Lymphaticovenular anastomosis compared to standard care for prevention of lymphoedema development

Patient or population: prevention of lymphoedema development

Setting: hospital

Intervention: lymphaticovenular anastomosis

Comparison: standard care

\begin{tabular}{|c|c|c|c|c|c|c|}
\hline \multirow[t]{2}{*}{ Outcomes } & \multicolumn{2}{|c|}{ Anticipated absolute effects ${ }^{\star}(95 \% \mathrm{Cl})$} & \multirow{2}{*}{$\begin{array}{l}\text { Relative effect } \\
(95 \% \mathrm{Cl})\end{array}$} & \multirow{2}{*}{$\begin{array}{l}\text { № of partici- } \\
\text { pants } \\
\text { (studies) }\end{array}$} & \multirow{2}{*}{$\begin{array}{l}\text { Certainty of the evi- } \\
\text { dence } \\
\text { (GRADE) }\end{array}$} & \multirow[t]{2}{*}{ Comments } \\
\hline & Risk with standard care & $\begin{array}{l}\text { Risk with lymphaticovenular anas- } \\
\text { tomosis }\end{array}$ & & & & \\
\hline \multirow{2}{*}{$\begin{array}{l}\text { Development of } \\
\text { LE }\end{array}$} & \multicolumn{2}{|l|}{ Study population } & \multirow{2}{*}{$\begin{array}{l}\text { RR } 0.20 \\
\text { (0.06 to } 0.63 \text { ) }\end{array}$} & \multirow{2}{*}{$\begin{array}{l}95 \\
\text { (2 RCTs) }\end{array}$} & \multirow{2}{*}{$\begin{array}{l}\oplus \oplus \odot \ominus \\
\operatorname{LOW} 1,2,3,4\end{array}$} & \\
\hline & 319 per 1,000 & $\begin{array}{l}64 \text { per } 1,000 \\
(19 \text { to } 201)\end{array}$ & & & & \\
\hline
\end{tabular}

${ }^{*}$ The risk in the intervention group (and its $95 \%$ confidence interval) is based on the assumed risk in the comparison group and the relative effect of the intervention (and its $95 \% \mathrm{Cl})$.

Cl: Confidence interval; RR: Risk ratio

\section{GRADE Working Group grades of evidence}

High certainty: We are very confident that the true effect lies close to that of the estimate of the effect

Moderate certainty: We are moderately confident in the effect estimate: The true effect is likely to be close to the estimate of the effect, but there is a possibility that it is

substantially different

Low certainty: Our confidence in the effect estimate is limited: The true effect may be substantially different from the estimate of the effect

Very low certainty: We have very little confidence in the effect estimate: The true effect is likely to be substantially different from the estimate of effect

1 The surgical intervention groups were small: In Boccardo 2009 the preventive protocol was followed for 25 women of which seven underwent LVA primarily and the number undergoing LVA at a later stage was not reported. In Boccardo 2011, all 23 participants in the intervention group had LVA done at the time of axillary clearance.

2 In Boccardo 2009, the control group received physical therapy and compression garments only after lymphoedema was detected whereas the intervention group received these as a preventive measure already before any lymphoedema was detected. Therefore, the difference detected between the two groups cannot be attributed solely to the LVA done. In Boccardo 2011, neither of the groups received any compression treatments which means that the effect of the intervention was not compared with the standard treatment but no treatment at all.

3 The study group allocation was not concealed and the assessment was not blinded in either of the included studies. Therefore, we downgraded the certainty of the evidence by 1 point for risk of bias

4 Due to the small number of participants in each trial and wide confidence intervals, we downgraded the certainty of evidence by 1 point for imprecision. 


\section{Summary of findings 2. Vascularised lymph node transfer compared to standard care for treatment of arm lymphoedema}

\section{Vascularised lymph node transfer compared to standard care for treatment of arm lymphoedema}

Patient or population: treatment of arm lymphoedema

Setting: hospital

Intervention: vascularised lymph node transfer

Comparison: standard care

\begin{tabular}{|c|c|c|c|c|}
\hline \multirow[t]{2}{*}{ Outcomes } & Relative effects ${ }^{\star}(95 \% \mathrm{Cl})$ & \multirow{2}{*}{$\begin{array}{l}\text { № of participants } \\
\text { (studies) }\end{array}$} & \multirow{2}{*}{$\begin{array}{l}\text { Certainty of the evi- } \\
\text { dence } \\
\text { (GRADE) }\end{array}$} & \multirow[t]{2}{*}{ Comments } \\
\hline & Vascularised lymph node transfer vs standard care & & & \\
\hline Reduction of LE (\%) & $\begin{array}{l}\text { MD } 39 \text { lower } \\
\text { ( } 47.37 \text { lower to } 30.63 \text { lower) in the intervention group }\end{array}$ & $\begin{array}{l}36 \\
(1 \mathrm{RCT})\end{array}$ & $\begin{array}{l}\oplus \ominus \ominus \ominus \\
\text { VERY LOW 1,2,3 }\end{array}$ & \\
\hline Number of infections per year & $\begin{array}{l}\text { MD } 1.22 \text { lower } \\
\text { (2 lower to } 0.44 \text { lower) in the intervention group }\end{array}$ & $\begin{array}{l}36 \\
(1 \mathrm{RCT})\end{array}$ & $\begin{array}{l}\oplus \ominus \ominus \ominus \\
\text { VERY LOW } 1,2,4\end{array}$ & \\
\hline $\begin{array}{l}\text { Pain score }(1-10 ; \text { where } 1 \text { = no pain; } \\
10=\text { extreme pain) }\end{array}$ & $\begin{array}{l}\text { MD } 4.16 \text { lower } \\
\text { (5.17 lower to } 3.15 \text { lower) in the intervention group }\end{array}$ & $\begin{array}{l}36 \\
(1 \mathrm{RCT})\end{array}$ & $\begin{array}{l}\oplus \ominus \ominus \ominus \\
\text { VERY LOW 1,2,3 }\end{array}$ & \\
\hline $\begin{array}{l}\text { Heaviness score ( } 1-10 \text {; where } 1=\text { no } \\
\text { heaviness; } 10=\text { extreme heaviness) }\end{array}$ & $\begin{array}{l}\text { MD } 4.27 \text { lower } \\
\text { (5.74 lower to } 2.8 \text { lower) in the intervention group }\end{array}$ & $\begin{array}{l}36 \\
(1 \mathrm{RCT})\end{array}$ & $\begin{array}{l}\oplus \ominus \ominus \ominus \\
\text { VERY LOW 1,2,3 }\end{array}$ & \\
\hline $\begin{array}{l}\text { Function score ( } 1-10 ; \text { where } 1= \\
\text { good function; } 10=\text { poor function) }\end{array}$ & $\begin{array}{l}\text { MD } 3.77 \text { lower } \\
\text { (4.89 lower to } 2.65 \text { lower) in the intervention group }\end{array}$ & $\begin{array}{l}36 \\
(1 \mathrm{RCT})\end{array}$ & $\begin{array}{l}\oplus \ominus \ominus \ominus \\
\text { VERY LOW 1,2,3 }\end{array}$ & \\
\hline
\end{tabular}

${ }^{*}$ The risk in the intervention group (and its $95 \%$ confidence interval) is based on the assumed risk in the comparison group and the relative effect of the intervention (and its $95 \% \mathrm{Cl}$ ).

Cl: Confidence interval; MD: mean difference

\section{GRADE Working Group grades of evidence}

High certainty: We are very confident that the true effect lies close to that of the estimate of the effect

Moderate certainty: We are moderately confident in the effect estimate: The true effect is likely to be close to the estimate of the effect, but there is a possibility that it is substantially different

Low certainty: Our confidence in the effect estimate is limited: The true effect may be substantially different from the estimate of the effect

Very low certainty: We have very little confidence in the effect estimate: The true effect is likely to be substantially different from the estimate of effect

1 The control group in Dionyssiu 2016 study received no physical or compression treatments for the 12 months prior to the final assessment and thus did not receive the current 
We downgraded the certainty of evidence by one point due to risk of bias because the participants and the personnel were not blinded to the treatment, 3 We downgraded the certainty of evidence by two points due to imprecision (small number of participants from one study and wide confidence intervals). 


\section{B A C K G R O U N D}

\section{Description of the condition}

Breast cancer is the most common type of cancer amongst women worldwide (Globocan 2012). Advances in treatment for breast cancer mean that more women are surviving and living with the consequences of the cancer and its treatment. One common and distressing sequelae of breast cancer treatment is lymphoedema (LE) (Hayes 2008). LE describes a condition where an excess of fluid builds up in the subcutaneous tissue of the arms, usually because of impairment to the outflow of lymphatic fluid from an affected area. Lymph or lymphatic fluid contains circulating tissue fluid and infection fighting white blood cells. The aetiology of the imbalance between production and drainage can be either congenital or acquired, so-called primary or secondary LE, respectively (Rockson 2008). Secondary LE is more common and has a variety of causes, including infection, cancer, radiation therapy, and surgery. Worldwide, the most common cause of LE is filariasis, caused by infection with the parasite Wuchereria bancrofti, whereas in the developed world the most common cause is malignancy and its treatment (Doscher 2012). As breast cancer is very common, its treatment is a major cause of secondary LE.

LE may occur after breast cancer treatment due to damage or destruction of the upper limb lymphatic drainage system, by either surgery or radiotherapy, or both, or owing to the destructive effects of the cancer itself (Brennan 1996). Estimates of the incidence of LE after breast cancer treatment vary widely depending on the type of treatment undergone and the diagnostic criteria for LE. At five years post-operation, $5 \%$ of patients who have had sentinel node biopsy, a surgery in which only a few lymph nodes are removed for analysis, develop measurable LE compared to $16 \%$ of patients who have had an axillary dissection and thus removal of all lymph nodes in the area (McLaughlin 2008). Obstruction to lymphatic drainage and accumulation of lymph fluid in the tissues leads to swelling, thickening of skin and the fatty layer of tissue under the skin, fibrosis or scarring and eventually to elephantiasis with chronic enlargement of the limb (Doscher 2012). The International Society of Lymphology staging system is the most universally accepted system for assessing the degree of LE (ISL 2009). In stage 0 disease, LE is subclinical, with no swelling despite evidence of impaired lymphatic transport; in stage 1 , disease swelling is evident but goes down with limb elevation; in stage 2, the swelling is persistent and fibrosis of the subcutaneous tissues becomes evident; and in stage 3, there is thickening of the skin with fatty deposits and lymphostatic warts, so called elephantiasis (ISL 2009).

Patients with LE may experience significant morbidity related to their condition including loss of limb function, discomfort, and disfigurement (Brennan 1996). LE may also be complicated by infections of the affected soft tissue and lymph vessels (cellulitis and lymphangitis) (Shih 2009). Although not a life-threatening condition, LE can cause great distress for breast cancer survivors, both through the physical effects, described above, and its psychological consequences (Bulley 2013). It can act as a constant reminder of previous disease and attract unwanted attention from others (Petrek 1998). Until recently, the effects that LE can have on a patient's quality of life have been underestimated. This is being addressed by the development of condition-specific quality of life assessment tools (Keeley 2010).
Measurement of limb circumference is the most commonly used method to evaluate LE as it is simple and widely available (Yamamoto 2013). Other tests are also used, including sentinel lymph node mapping with radioactive tracer in lymphoscintigraphy or radiocontrast material in lymphography, indocyanine green (ICG), and volume assessment based on computed tomography (CT), magnetic resonance imaging (MRI), measurement of water displacement and laser scanning (Bulley 2013; Yamamoto 2013). It is widely considered to be important to diagnose LE as early as possible in the natural history described above. This allows early intervention, including the provision of information and psychological support, and may prevent symptomatic LE formation and progression to severe disease (Yamamoto 2011). Objective evaluation of existing LE is important both to evaluate its extent and to assess interventions to reduce it.

\section{Description of the intervention}

Various conservative strategies are used for women with breast cancer to decrease the risk of developing LE (Stuiver 2012) and to manage it, once developed (Preston 2008). These include exercise, patient education, monitoring, compression therapy, manual lymph drainage, and lymph taping (kinesiotaping). There is no consensus as to the optimal conservative management.

Surgery is traditionally the option of last resort, when conservative measures have failed (Vignes 2002). Indications for surgery include insufficient LE reduction by well performed medical and physical therapy, recurrent episodes of lymphangitis, intractable pain, decreasing limb function, patient's dissatisfaction with conservative methods, and the patient's wish to proceed to surgery (Campisi 2010). However, patients and surgeons are increasingly undertaking modern surgical interventions early in the disease process in the hope of preventing or reversing the swelling arising from impaired lymph flow changes (Boccardo 2011).

These interventions include liposuction, lymph node transfer, and lymphaticovenular anastomosis (LVA) (Becker 2006; Brorson 1997; Campisi 2004; Nagase 2005). The techniques aim to either directly reduce the volume of the arm by removing fat and fibrous tissue (liposuction), bypass the obstruction to lymphatic outflow by creating a direct route for lymphatic fluid to re-enter the circulation in the arm (LVA), or improve lymphatic drainage from the arm possibly by the creation of new lymphatic channels (lymph node transfer).

\section{How the intervention might work}

Chronic LE causes an increase in swelling of subcutaneous fat tissue, which leads to deformity and limb swelling. This is the rationale behind liposuction for LE where the hypertrophied adipose tissue is removed in a circumferential fashion through cannulae inserted into small incisions, usually under general anaesthesia (Brorson 2002; Damstra 2009). Lifelong compression garments are then needed to prevent postoperative recurrence of the lymphoedema (Brorson 2002; Damstra 2009).

Microsurgical lymphatic reconstruction is another surgical intervention for LE, most often in the form of LVA, though occasionally an unaffected lymphatic channel is used to bypass the area of lymphatic damage, a method known as a lymphaticolymphatic bypass (Lee 2011). LVA consists of anastomosing, or connecting, lymphatic vessels to a small vein in the subcutaneous 
tissue. This returns the lymph fluid to the circulation peripherally, meaning it no longer has to pass through the area of lymphatic damage to return to the circulatory system. Dye is used to find healthy, functioning lymphatics and to confirm that the connection between the vessels is open. Lymphoscintigraphy or ICG lymphography can be used during follow-up to confirm ongoing anastomosis patency (Campisi 2010).

Lymph node transfers take healthy lymph nodes from an unaffected limb and move them to either the armpit or elbow of the affected arm (Becker 2006). The aim of the technique is for the transplanted lymph nodes to take over lymphatic drainage from local lymph nodes which have been damaged or removed by surgery (Becker 2006). Notably, the precise mechanism of action of lymph node transplant is complex and is not completely understood.

\section{Why it is important to do this review}

LE as a consequence of breast cancer treatment causes severe physical and psychosocial morbidity amongst this patient group. There is no consensus as to which of the available surgical options described above provides the best outcome in this patient group, both in terms of prevention and treatment of established disease. We aim to clarify the indications, benefits, and uncertainties in the field.

\section{OB JECTIVES}

1. To assess and compare the efficacy of surgical interventions for the prevention of the development of lymphoedema (LE) in the arm after breast cancer treatment.

2. To assess and compare the efficacy of surgical interventions for the treatment of established LE in the arm after breast cancer treatment.

\section{METHO D S}

\section{Criteria for considering studies for this review}

\section{Types of studies}

We considered all types of randomised controlled trials (RCTs) that compared a surgical intervention for the treatment or prevention of LE in the arm after breast cancer treatment to either standard intervention (conservative measures such as compression garments, lymphatic massage, bandaging, and intermittent pneumatic compression), placebo intervention (surgery performed without the critical surgical step), or another surgical intervention that was included in this review (see types of intervention).

All studies that presented predefined, objective criteria for diagnosing or assessing LE, or both, were considered eligible. These criteria (Bulley 2013; Yamamoto 2013) included, but were not limited to:

1. measurements of tissue volume and distribution, such as water displacement, tape measure, and perometry;

2. determination of limb composition, such as tonometry, skinfold thickness, dual energy $\mathrm{x}$-ray absorptiometry, and bioelectrical impedance analysis;

3. imaging tests, such as lymphoscintigraphy, lymphangiography, MRI, ultrasound, and CT scanning.

\section{Types of participants}

We included participants of both sexes and all ages who had treatment for their breast cancer. This included any type of surgery, radiotherapy, chemotherapy, or combination of these.

\section{Types of interventions}

We considered any surgical intervention for the treatment or prevention of secondary LE of the arm after breast cancer treatment. Both reductive and reconstructive techniques were considered, including, but not limited to:

- liposuction;

- lymphaticovenular anastomoses;

- lymphatico-lymphatic bypass;

- lymph node transfer.

\section{Types of outcome measures}

\section{Primary outcomes}

All outcome measures were assessed at the latest time point reported in the study.

\section{Prevention}

- The development of LE at the latest time point specified in the study

\section{Treatment}

- The percentage reduction in LE between randomisation and the end of follow-up, as measured by a validated system for limb volume measurement

\section{Secondary outcomes}

Secondary outcome measures were as follows.

1. Patient-reported outcomes using validated questionnaires, such as the condition-specific quality of life measure for limb lymphoedema (LYMQOL) which accounts for not only physical symptoms but also social function and psychological effects (Keeley 2010). Other similar validated questionnaires include the Upper Limb Lymphedema 27 (ULL-27) (Launois 2002) and Freiburg Life Quality Assessment-Lymphedema (FLQA-L) (Augustin 2005).

2. Ability to discontinue further interventions for LE; for example, this may be non-adherence to or the number of dropouts from continued use of compression therapy, manual therapy, or lymph taping.

3. Surgical complications related to LE surgery, such as seroma, lymphorrhoea, wound dehiscence, wound infections.

4. Long-term complications, such as rate of cellulitis, lymphangitis, lymphadenitis, skin ulcers, and lymphorrhoea.

\section{Search methods for identification of studies}

We did not impose any language or publication date restrictions.

\section{Electronic searches}

For published trials, we searched the following on 2 November 2017. 
- The Cochrane Breast Cancer Group (CBCG) Specialised Register. Details of the search strategies used by the CBCG for the identification of studies and the procedure used to code references are outlined in the Group's module (www.mrw.interscience.wiley.com/ cochrane/clabout/articles/BREASTCA/frame.html). Trials with the key words 'lymphoedema', 'lymphedema', 'breast cancer', 'axillary clearance', 'axillary lymphadenectomy', 'axillary dissection', 'lymphaticovenular anastomosis', 'lymphaticovenous anastomosis', 'LYMPHA', 'lymph node transfer', 'lymph node flap', 'liposuction', 'lymphatic bypass', 'prevention', and 'treatment' were extracted and considered for inclusion in the review.

- Cochrane Central Register of Controlled Trials (CENTRAL). See Appendix 1.

- MEDLINE via OvidSP. See Appendix 2.

- Embase via EMBASE.com (1947 to January 2015) and OvidSP (January 2015 to November 2017). See Appendix 3 for the search strategy.

- The Cumulative Index to Nursing and Allied Health Literature (CINAHL) through EBSCO (1980 to May 2013). See Appendix 4 for the search strategy.

For prospectively registered and ongoing trials, we searched:

- the World Health Organization (WHO) International Clinical Trials Registry Platform (ICTRP) search portal (http:// apps.who.int/trialsearch/Default.aspx). See Appendix 5 for the search strategy;

- ClinicalTrials.gov (http://clinicaltrials.gov/).

\section{Searching other resources}

Three review authors independently searched the reference lists of included studies for additional eligible studies.

\section{Data collection and analysis}

\section{Selection of studies}

Three review authors (PM, NL, VA) independently determined the eligibility of each study. Three authors reviewed the titles and abstracts of all citations found through the search strategy previously described. A copy of the full article for each citation reporting a potentially eligible study was obtained, and three review authors (PM, NL, VA) independently applied the eligibility criteria; any discrepancies were resolved by consensus through discussion with a fourth review author (DF). Where necessary and possible, additional information was sought from the principal investigator of the study concerned. Any exclusions from the review of a potentially eligible study were justified in the final report.

\section{Data extraction and management}

Three review authors (PM, NL, VA) independently extracted the data for each included study using a pre-designed data extraction pro forma. Data were extracted on the details of the study (first author, year of publication, journal, publication status, period and country of study, sources of funding, study design, sample size); participants' characteristics (age, sex, type of disease, stage of disease, type of surgery, and prior treatment status); risk of bias assessment; details of the intervention; duration of followup; and the primary and secondary outcomes. A fourth review author (DF) resolved any discrepancies regarding data extraction, and consensus was reached. The most complete data set feasible was assembled. The study authors were contacted with the aim of acquiring additional information on the data presented.

\section{Assessment of risk of bias in included studies}

Three review authors (PM, NL, VA) independently assessed each study for risk of bias using the Cochrane Collaboration's 'risk of bias' tool (Higgins 2011). We considered selection bias, performance bias, detection bias, attrition bias, and reporting bias for each individual study. Any discrepancies were resolved by consensus through discussion with a fourth author (DF). We contacted study authors for additional information to enable the assessment of the risk of bias but did not receive any further information. We acknowledge that there is no accepted definition of high risk of bias, so we chose the threshold as those trials with greater than or equal to three of seven domains (random sequence generation, allocation concealment, blinding of participants and personnel, blinding of outcome assessment, incomplete outcome data, selective reporting, other bias) with high risk of bias when analysed with the Cochrane Collaboration's risk of bias tool to represent high risk of bias studies. In addition, if there were some risk of bias concerns on multiple domains, we classified the study to be an unclear risk of bias overall.

\section{Measures of treatment effect}

We planned to use hazard ratios (HRs) with 95\% confidence intervals (Cls) to evaluate the comparative times to development of LE after preventive LE surgery and also time to the development of complications related to surgery or to LE itself. However, this was not possible in this review version as there was insufficient detail in the reports of included studies, and the authors did not respond to requests for further information. In future updates, this analysis will be considered.

Risk ratios (RR) with $95 \% \mathrm{Cl}$ were used to quantify the risk of developing LE, surgical complications, and LE complications.

Differences in continuous variables, such as those measuring the percentage reduction of LE after treatment or the psychosocial well-being of participants with LE, were estimated as mean differences (MDs). The amount of LE was calculated as the excess volume in the affected limb compared to the unaffected limb, expressed as a percentage of the volume of the unaffected limb. The patient-reported measures of LE-related well-being assessed on a 10 point scale (where 1 was good; 10 was bad) were reported as means (at baseline and post-intervention) and change from baseline scores.

\section{Unit of analysis issues}

All included studies addressed people with unilateral LE after breast cancer with each participant randomly assigned. Therefore, no unit of analysis issues arose. With the surgical interventions that were done after a period of observation or nonsurgical treatment, we considered only the postoperative intervention period in the analysis.

\section{Dealing with missing data}

We based our analysis only on participants who completed the study and made no assumptions about loss to follow-up. All analyses were done by intention-to-treat (Hollis 1999). If participants were allocated to one intervention (for example 
LVA), but after randomisation underwent a different intervention (for example lymphatico-lymphatic bypass), they were analysed according to their randomised allocation. In Boccardo 2009, 89\% of participants randomised were assessed at two years. In Boccardo 2011 and Dionyssiou 2016, no participants were lost to follow-up after randomisation. No missing data was identified to necessitate contacting study authors for additional information.

\section{Assessment of heterogeneity}

We examined heterogeneity using the $\mathrm{Chi}^{2}$ test with significance set at a $P$ value of 0.10 , and measured the quantity of heterogeneity using the $\mathrm{I}^{2}$ statistic (Higgins 2002).

Thresholds for the interpretation of the 12 statistic can be misleading. A rough guide to interpretation is:

- $0 \%$ to $40 \%$, might not be important;

- $30 \%$ to $60 \%$, may represent moderate heterogeneity;

- $50 \%$ to $90 \%$, may represent substantial heterogeneity;

- $75 \%$ to $100 \%$, considerable heterogeneity.

We took factors such as clinical and methodological heterogeneity, along with whether the heterogeneity was in the magnitude of effect or in the direction of effect, into account while interpreting the $1^{2}$ statistic, particularly where there was overlap in the ranges defining levels of heterogeneity.

\section{Assessment of reporting biases}

We compared the reported outcomes with those stated in the methods of the studies and also those listed in clinical trials registries as both primary and secondary outcomes (for example http://www.clinicaltrials.gov/). We planned to assess publication bias by creating a funnel plot using software within Review Manager 5.2 (RevMan 2012) if at least 10 studies were identified. Only three studies were included in this review so a funnel plot was not used.

\section{Data synthesis}

We presented a narrative overview of the included studies. Where appropriate, we undertook meta-analyses of outcome data using Review Manager software (RevMan 2012).

For time-to-event data, such as time to development of LE in a prevention study, we planned to plot (and, if appropriate, pool) estimates of the $\mathrm{HR}$ and $95 \% \mathrm{Cl}$ as presented in the study reports using the generic inverse variance method in the Review Manager software (RevMan 2012). However, this was not possible in this review version because there was insufficient detail on time-to event data in the reports, and the authors did not respond to requests for further details. Comparison of the primary outcome for prevention was instead reported as a risk ratio at the final time point.

For dichotomous outcomes, such as surgical wound infection, we planned to present the summary estimate as a RR with $95 \% \mathrm{Cl}$.
For continuous outcomes measured in the same way across studies, for example, measurements of limb volume, we planned to present a MD with $95 \% \mathrm{Cl}$. We planned to present a standardised mean difference (SMD) for studies measuring the same outcome using different methods. The three studies identified did not enable these meta-analyses.

To grade the certainty of the evidence, GRADE profiler software (GRADE) was used and 'Summary of findings' tables were produced for the six prespecified outcomes for the prevention and treatment of LE.

\section{Subgroup analysis and investigation of heterogeneity}

We planned to conduct subgroup analyses for participants with different types of axillary surgery and adjuvant treatments as well as those with normal or high body mass index. However, all three studies identified enrolled only participants who had axillary clearance and the study samples were too small to allow any subgroup analyses.

In future review updates, if possible, the following will be considered for possible subgroup analysis:

1. patients with sentinel lymph node biopsy and complete lymph node clearance;

2. patients treated with and without radiotherapy to the axilla;

3. patients treated with and without radiotherapy to any area (axilla, breast, chest wall);

4. patients treated with and without chemotherapy;

5. patients with a body mass index above 30 or below 30 ;

6. patients with different stages of lymphoedema.

\section{Sensitivity analysis}

We planned to perform sensitivity analysis, through excluding studies with a high risk of bias from the analysis. We acknowledged that there is no accepted categorisation of high risk of bias and therefore judged a study to be at high risk of bias if greater than or equal to three of seven domains were judged to be at high risk of bias. However, only three studies were identified and a sensitivity analysis was not conducted.

\section{RES U L T S}

\section{Description of studies}

\section{Results of the search}

A total of 792 records were retrieved (see Figure 1). Fourteen records were considered potentially relevant, and three of these met our predefined inclusion criteria (Boccardo 2009; Boccardo 2011; Dionyssiou 2016). There were no ongoing studies or studies awaiting classification identified. 
Figure 1. Study flow diagram.

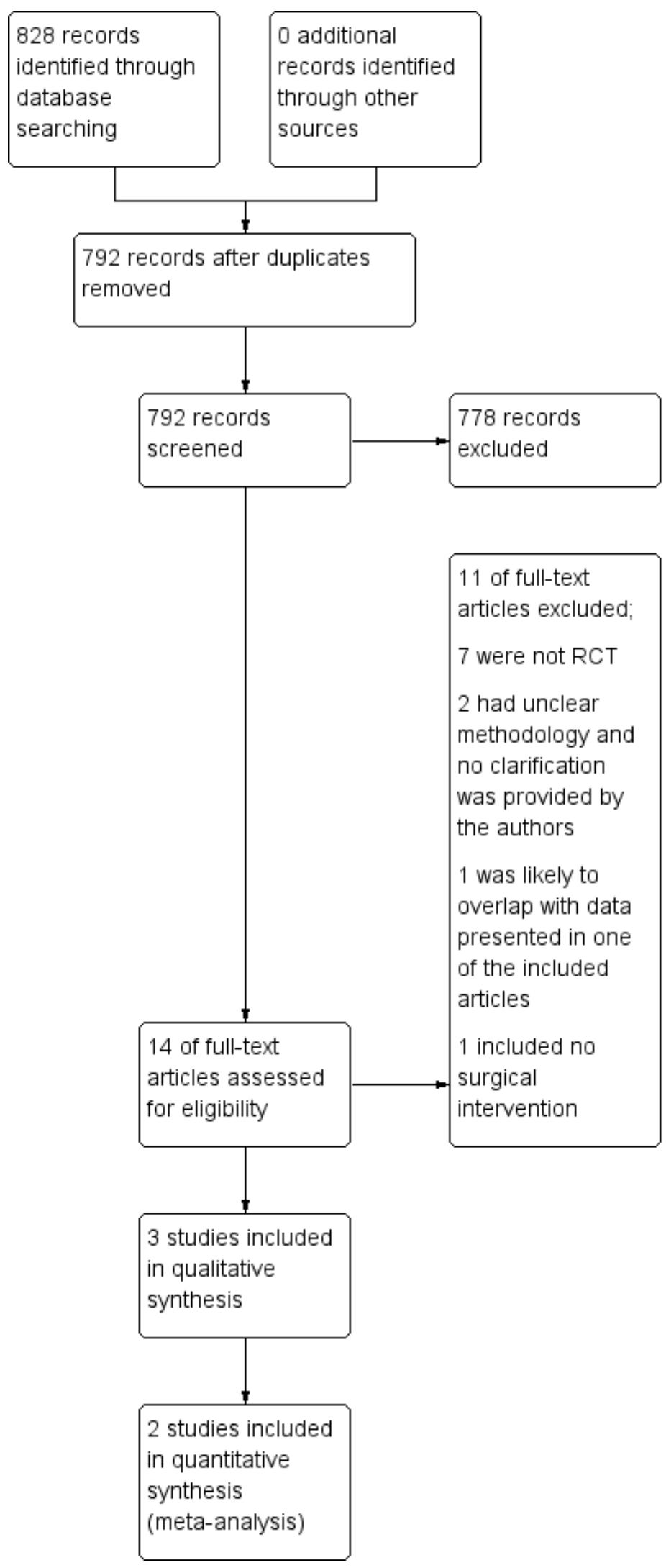




\section{Included studies}

Three studies were included: two studies reported on the effectiveness of lymphaticovenular anastomosis as part of preventive management protocols in the prevention of breast cancer-related lymphoedema (Boccardo 2009; Boccardo 2011) and one study (Dionyssiou 2016) reported on the effectiveness of vascularised lymph node transfer in the treatment of established breast cancer-related lymphoedema, comparing outcomes at 18 months between two groups of participants - the intervention group - who had lymph node transfer and six months of combination physical and compression therapy, and the comparator group - who had six months of combination physical and compression therapy only. All participants in the three studies were women. Lymphoedema was defined as an arm volume increase of $100 \mathrm{~mL}$ (Boccardo 2011) or $200 \mathrm{~mL}$ (Boccardo 2009) in comparison with the preoperative volume of that arm or as a percentage difference in volume of the affected arm in comparison with the unaffected arm (Dionyssiou 2016). Refer to the Characteristics of included studies for additional details.

\section{Excluded studies}

Of the eleven potentially relevant studies that were eventually excluded, seven studies were determined to not be randomised controlled trials after full-text review (Brorson 1997; Brorson 1998; Brorson \& Svensson 1998; Brorson 2000; Ciudad 2017; Maldonado 2011; Saaristo 2012); two studies had incomplete reporting of the study design making it impossible to determine whether they were randomised trials (Campisi 2006; Youssef 2010); one study was reported as an abstract with results that likely overlapped with another study which had already been assessed in this review (Campisi 2014); and one study was determined to not have evaluated a surgical technique (Hou 2008).

Efforts were made to contact authors to clarify their methods where there were uncertainties, but there was either no response to our efforts or no available contact details (Campisi 2006; Campisi 2014; Youssef 2010). Refer to the Characteristics of excluded studies.

\section{Risk of bias in included studies}

See Figure 2 for visual summaries of the 'risk of bias' assessment. All three studies, Boccardo 2009, Boccardo 2011 and Dionyssiou 2016, were judged to be at unclear risk of bias due to multiple domains in each study being at unclear or high risk of bias. 
Figure 2. Risk of bias summary: review authors' judgements about each risk of bias item for each included study.

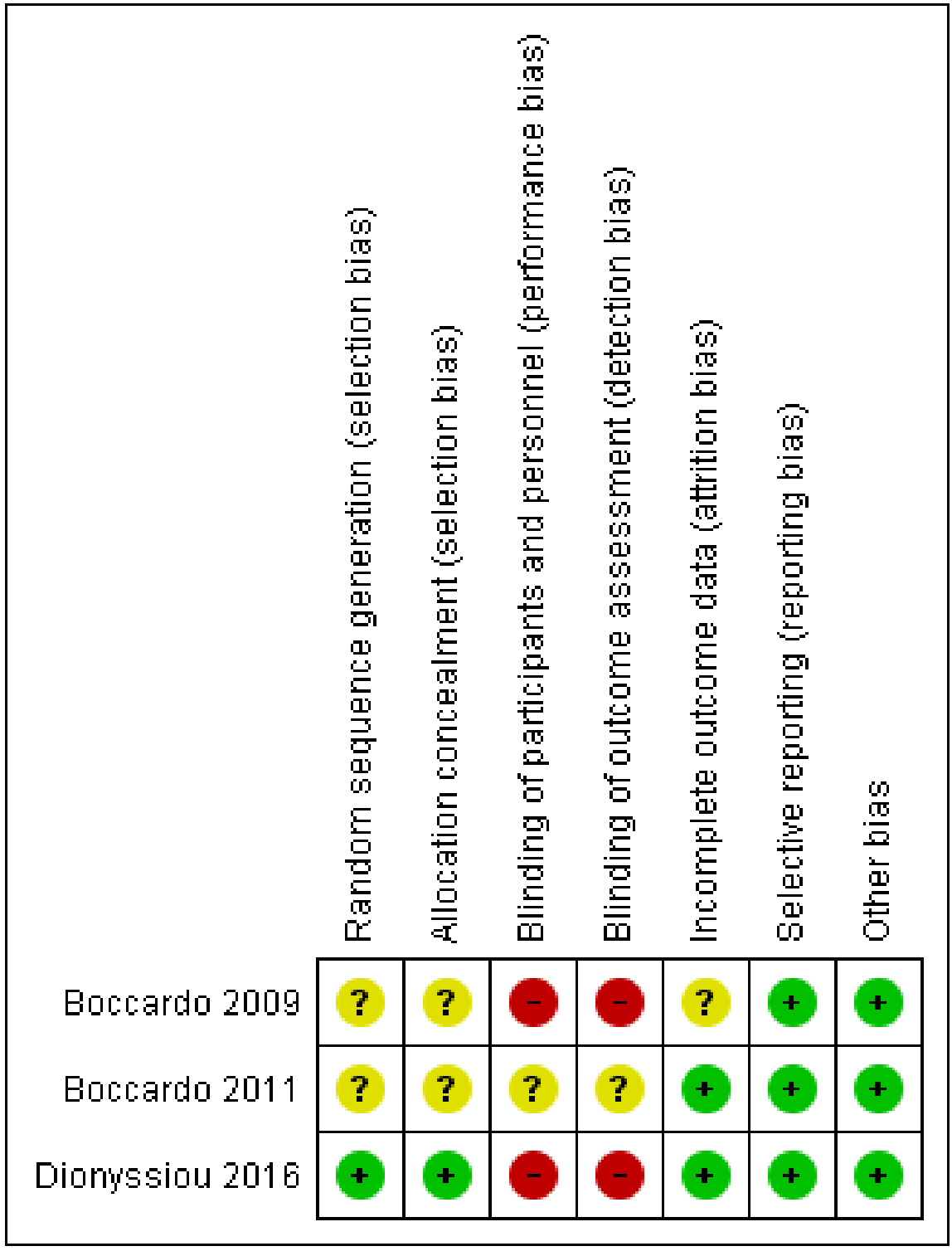

\section{Allocation}

Both Boccardo 2009 and Boccardo 2011 were rated as unclear risk for selection bias. The studies mentioned only that they "randomly assigned" participants to different groups, without describing how the randomisation was achieved. There was also no mention as to when the allocation was revealed and whether steps were taken to ensure strict implementation of the schedule of random assignments by those enrolling participants into the different treatment arms. However, it was notable that, in both studies, no statistically significant, or potentially clinically important, differences in participants' baseline characteristics were noted between the treatment and control groups; comparisons included age, body mass index, the presence of metastatic lymph nodes, baseline lymphoedema volume, radiotherapy, infection, etc (Boccardo 2009; Boccardo 2011).

Dionyssiou 2016 employed both a satisfactory method of random sequence generation using a "random number generator" and a conscious approach to conceal allocation by revealing allocation only after participants had been initially examined, assessed and recruited. These efforts resulted in an overall rating of low risk of selection bias for this study.

\section{Blinding}

Two of the studies had a high risk of performance and detection bias as, for each of the studies, the control group did not receive a surgical intervention (Boccardo 2009; Dionyssiou 2016) and it would be practically impossible to blind the surgeons and participants to the surgical treatments provided. Moreover, outcome assessors could not practically be reliably blinded to the intervention received because of the presence of surgical scarring and also participants' knowledge. In the third study (Boccardo 2011), the experimental surgical intervention was done during the same operation as standard care. However, it was not clear whether the participants were blinded to the treatment provided. 


\section{Incomplete outcome data}

For two studies, there were no concerns regarding attrition bias, and complete outcome data were reported for all participants (Boccardo 2011; Dionyssiou 2016). Boccardo 2009 reported that 6 , or $11 \%$, of their 55 participants did not complete follow-up. Unfortunately, no reasons were specified for failure to complete the follow-up assessments and partial data were included so it was unclear as to what impact this would have on the results.

\section{Selective reporting}

All three studies were rated as low risk for reporting bias (Boccardo 2009; Boccardo 2009; Dionyssiou 2016). Whilst no pretrial protocols were available, all results in these studies were reported as per the outcomes specified in the methods (Boccardo 2009; Boccardo 2009; Dionyssiou 2016). Notably, however, neither Boccardo 2009 nor Boccardo 2011 formally looked at surgical complications as an outcome to be assessed, and it was certainly unclear whether their participants suffered any complications as part of the procedure.

\section{Other potential sources of bias}

No other potential sources of bias were identified.

\section{Effects of interventions}

See: Summary of findings for the main comparison Lymphaticovenular anastomosis compared to standard care for prevention of lymphoedema development; Summary of findings 2 Vascularised lymph node transfer compared to standard care for treatment of arm lymphoedema

\section{Prevention}

\section{The development of $L E$}

Both Boccardo 2009 and Boccardo 2011 included the development of $L E$ as an outcome, reporting on a total of 95 participants. The statistical heterogeneity between the trials was low $\left(1^{2}=0 \%, \mathrm{P}\right.$ $=0.68$ ). Analysis using a fixed-effect model demonstrated that participants who had undergone lymphaticovenular anastomosis as a preventive measure had a reduced risk of developing lymphoedema during the 18-month (Boccardo 2011) and 24-month (Boccardo 2009) follow-up compared to those who had not (RR $0.20,95 \% \mathrm{Cl} 0.06$ to $0.63, \mathrm{P}=0.006$; low-certainty evidence ; Analysis 1.1 ; Figure 3).

Figure 3. Forest plot of comparison: 1 Development of LE, outcome: 1.1 Development of LE.

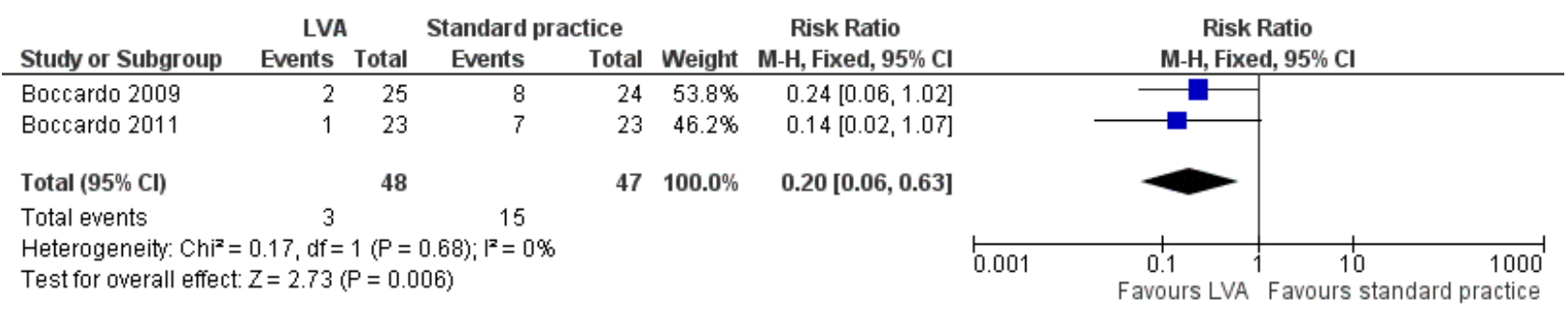

\section{Patient-reported outcomes}

The two studies did not evaluate patient-reported outcomes.

\section{Ability to discontinue further interventions for $L E$}

The two studies did not report on this outcome.

\section{Surgical complications (seroma, lymphorrhoea, wound dehiscence, wound infections)}

The two studies did not report on these outcomes.

Long-term complications (cellulitis, lymphangitis, lymphadenitis, skin ulcers, and lymphorrhoea)

The two studies did not report on these outcomes.

\section{Treatment}

\section{The percentage reduction of $L E$}

Dionyssiou 2016 reported a statistically significant difference $(57 \%$ versus $18 \%$ ) in mean limb volume reductions for participants who had undergone lymph node transfer in addition to standard care (i.e. physical and compression therapy) and those participants who had received standard care alone.This equated to a difference in volume reduction of $39.00 \%$ (95\% $30.63 \%$ to $47.37 \%$; 36 participants; very low-certainty evidence) between the two groups, favouring lymph node transfer over no treatment $(P<0.00001$; Analysis 2.1; Figure 4).

Figure 4. Forest plot of comparison: 2 Reduction of LE, outcome: 2.1 Reduction of LE [\%].

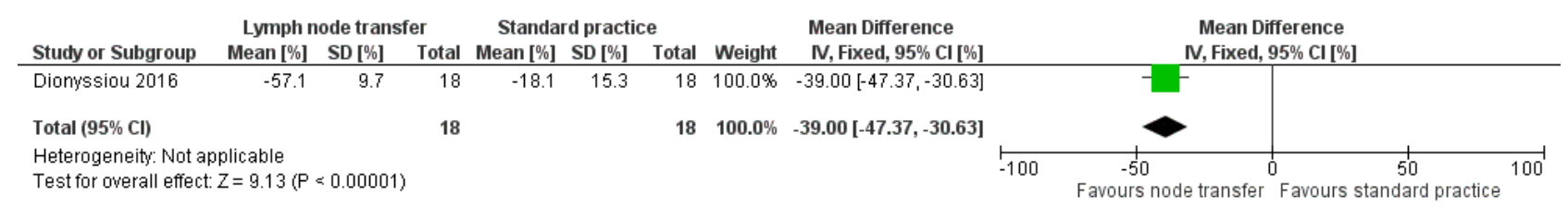




\section{Patient-reported outcomes}

Dionyssiou 2016 studied various patient-reported outcomes: pain, sensation of heaviness, and overall function, all of which were rated on a 10-point scale (Dionyssiou 2016). This scale ranged from 1 (e.g. no pain or good function) to 10 (e.g. extreme pain or very poor function). Those in the lymph node transfer group (plus with standard care) experienced a reduction in pain, heaviness sensation, and also improvements function scores compared to baseline, in contrast to effects that were statistically not significant amongst participants in the standard care alone group. The mean difference in pain reduction (MD $-4.16,95 \% \mathrm{Cl}-5.17$ to -3.15 ; very low-certainty evidence; Analysis 2.2), sensation heaviness reduction (MD $-4.27,95 \% \mathrm{Cl}-5.74$ to -2.80 ; very low-certainty evidence; Analysis 2.3), and overall functional improvement (MD $-3.77,95 \% \mathrm{Cl}-4.89$ to -2.65 ; very low-certainty evidence; Analysis 2.4) favoured lymph node transfer over no treatment.

\section{Ability to discontinue further interventions for $L E$}

The study did not report on this outcome.

\section{Surgical complications (seroma, lymphorrhoea, wound dehiscence, wound infections)}

Dionyssiou 2016 reported that lymph node transfer reduced the mean number of infections per year that participants experienced in the arm affected by LE, such as erysipelas, cellulitis, or lymphangitis. The reduction in the mean number of infections was greater for the surgical group with an MD $-1.22(95 \% \mathrm{Cl}-2.00$ to 0.44 ; very low-certainty evidence; Analysis 2.5 ).

\section{Long-term complications (cellulitis, lymphangitis,} lymphadenitis, skin ulcers, and lymphorrhoea)

The study did not report on these outcomes.

\section{DISCUSSION}

\section{Summary of main results}

Performing lymphaticovenular anastomosis as part of a preventive management protocol early during breast cancer treatment appears to reduce the risk of lymphoedema development in the arm on the affected side (based on the results of two studies). However, these two prevention studies did not report on important secondary outcomes. Vascularised lymph node transfer used in the treatment of established breast cancer-related lymphoedema may reduce limb volume, pain scores, heaviness sensation, and infections per year and improve overall function (based on one study). Important secondary outcomes such as long-term complications and ability to discontinue further interventions for treating lymphoedema were not collected in the study.

\section{Overall completeness and applicability of evidence}

Due to the lack of randomised controlled trials on the topic, our systematic review has been able to answer only one of a number of questions it could have potentially addressed. In particular, there were no eligible studies that compared the effectiveness of one surgical technique against another, and there were no eligible studies that looked at the efficacy of other known surgical techniques, such as liposuction and lymphatico-lymphatic bypass, in the treatment and/or prevention of breast cancer-related lymphoedema. Amongst the studies retrieved and included, there was also a lack of uniformity in the way lymphoedema was assessed, outcomes measured, and complications reported.

The two studies examining the use of lymphaticovenular anastomosis in the prevention of breast cancer-related lymphoedema included women who had undergone or were scheduled to undergo complete axillary dissection as part of their breast cancer treatment (Boccardo 2009; Boccardo 2011). The certainty of the evidence provided by these two studies was low. The studies included a total of only 95 participants, insufficient numbers for effective subgroup analysis, which would have been helpful, for example, in identifying participants' characteristics that may be more predictive of treatment success, informing future management pathways. It is also notable that these two studies only evaluated one outcome - the presence of lymphoedema. The authors did not formally report on patientreported outcome measures, postoperative complications, or the ability to discontinue with further interventions; and since the maximum follow-up time for the studies was only two years, long-term outcomes were unknown. The data from both studies came from only one surgical team based in Italy, which potentially reduces generalisability of the evidence.

One study evaluated the effectiveness of vascularised lymph node transfer, without the need for continued physical or compression therapy, in the treatment of established breast cancer-related lymphoedema of stage 2 severity, again potentially reducing generalisability of the evidence. (Dionyssiou 2016). The certainty of the evidence provided in this study was very low. Similar to Boccardo 2009 and Boccardo 2011, Dionyssiou 2016 was limited by both a relatively small number of study participants and a short follow-up period. Dionyssiou 2016 did look at a wider range of outcomes, however, to include not only the reduction of the number of infections per year, but also patient-reported outcome measures such as pain, sensation of heaviness, and function. Nevertheless, an important question this trial failed to answer was whether participants who underwent vascularised lymph node transfer experienced outcomes that were comparable to those who underwent complete decongestive physiotherapy, the current gold standard treatment of lymphoedema.The 'control' group in Dionyssiou 2016 had no physical or compression treatment for a total of 12 months prior to their final evaluation.

\section{Quality of the evidence}

The number of eligible studies for this review was low, and the conclusions were based on a total of only 131 participants. Whilst all three studies were randomised controlled trials, there were a number of design deficiencies. There was no evidence of random sequence generation or allocation concealment in two of the trials, and because of the surgical nature of the interventions, blinding of participants, personnel, and outcome measurement was, in some cases, impossible. Outcome data for Boccardo 2009 was incomplete because six participants failed to complete follow-up; no reasons or partial outcomes were reported. Additionally, our final rating of low risk for selective reporting in the Boccardo studies may be incorrect, since the authors did not formally mention patient-reported outcomes, postoperative complications, or the ability to discontinue with further interventions, which would have been expected for modern studies analysing surgical interventions. Increased follow-up times would have also made the findings of this systematic review more authoritative. 
With respect to the evidence for the use of lymphaticovenular anastomosis in the prevention of lymphoedema, the heterogeneity between Boccardo 2009 and Boccardo 2011 was low and the results for the main outcome were consistent. Whilst the participants' demographic characteristics, interventions, and methods were slightly different, both studies suggested a decreased risk of lymphoedema development when lymphaticovenular anastomosis was performed early as part of or after breast cancer treatment. Overall, the certainty of the evidence supporting the use of lymphaticovenular anastomosis provided in these studies was graded as low.

The Dionyssiou 2016 showed clear, statistically significant differences, for five different outcomes, of the effectiveness of vascularised lymph node transfer for the treatment of established breast cancer-related stage 2 lymphoedema. Overall, the certainty of the evidence provided in this study was very low. The major shortcoming of the study, however, is arguably whether this trial addressed the correct question. Specifically, it compared participants who had undergone vascularised lymph node transfer against participants who received no treatment for 12 months prior to the final evaluation of their lymphoedema. Indeed, a more appropriate method would have been to compare their surgical outcomes with participants who have been treated with gold standard complex decongestive therapy throughout the duration of follow-up. This would have provided valuable insight as to whether participants could truly completely do away with time-consuming physical and compression therapy after surgical treatments for breast cancer-related lymphoedema. Furthermore, the sensitivity of the 10-point scale used was not addressed, questioning the clinical significance of the statistically significant changes detected for the various domains.

\section{Potential biases in the review process}

The potential for bias in the review process was low to moderate. The literature search was conducted by the Cochrane Breast Cancer Group according to accepted standards. We are therefore confident that studies on this topic have been captured in this review. Additionally, study selection was undertaken independently by three review authors (PM, NL, and VA), working in strict adherence to agreed upon inclusion/exclusion criteria. Disagreements were resolved by a senior reviewer (DF).

However, because non-English language articles were identified in the search and the four review authors are English language speaking, non-English language material could have been missed. The authors attempted to prevent this from happening by having any non-English language material reviewed and assessed by medically-trained colleagues fluent in the non-English language in question. Notably, none of the non-English language articles met the inclusion criteria for this review.

Overall, it is difficult to exclude publication bias secondary to outcomes that have not been published because the results were not significant or because the trials were not accepted for publication by journal editors.

\section{Agreements and disagreements with other studies or reviews}

Five earlier systematic reviews reported on the effectiveness of surgical intervention for extremity lymphoedema and were mainly based on case series (Carl 2017; Cormier 2012; Leung 2015; Penha 2013; Scaglioni 2017). Two of these focused specifically on breast cancer-related lymphoedema (Leung 2015; Penha 2013); one focused specifically on the lymphovenous anastomosis technique (Scaglioni 2017); and the remaining two additionally covered lymphoedema affecting the lower limbs (Carl 2017; Cormier 2012). Between the earliest and latest of the above reviews, it is clear that there has been an explosion of research regarding this topic in recent years; indeed, whilst Cormier 2012's comprehensive search returned only 20 eligible studies in 2010 , a similarly comprehensive search done by Carl 2017 returned 69 eligible studies in 2016 (Cormier 2012; Carl 2017). Nevertheless, the major conclusions that could be drawn from all the above studies are the same and concur with the perspective reached by the present Cochrane reviewers: as there is very low-certainty evidence of the effectiveness of surgical intervention for the treatment of lymphoedema, the conclusions that could be drawn from the evidence are limited overall both by the relatively short follow-up periods and the small number of randomised controlled trials.

With respect to specific recommendations, Penha 2013 favoured vascularised lymph node transfer, because from their qualitative assessment of the literature at the time, it was the only technique which provided evidence to allow for the discontinuation of postoperative conservative therapy. Furthermore, they reasoned that the technique could theoretically be combined with autologous breast reconstruction, which might make it easier to incorporate into already established breast cancer management programs (Penha 2013). Leung 2015 agreed with the potential benefit of utilising vascularised lymph node transfer as part of planned breast reconstruction, but argued that the risk and potential morbidity associated with the procedure (e.g. donor site lymphoedema, scarring, cosmetic concerns, etc.) make it less preferable to the less invasive lymphovenous approach in the treatment of less severe lymphoedema up to International Society of Lymphology (ISL) stage lla (Leung 2015). From their systematic review and meta-analyses, Carl 2017 further clarified the potential treatment algorithm, suggesting lymphovenous anastomosis as the preferred method for Tc-99m lymphoscintigraphy-defined partially obstructed lymphoedema up to ISL stage II, but vascularised lymph node transfer, liposuction, or excision for more severe cases with total lymphatic obstruction.

For want of randomised controlled trials, this present review is unable to further clarify the validity of the treatment algorithm proposed by Carl 2017. However, this review does make a case for extending the proposed algorithm to include the use of lymphovenous anastomosis for the prevention of breast cancerrelated lymphoedema. It also lends further evidence to support the use of vascularised lymph node transfer for those with more severe lymphoedema.

\section{AUTHORS' CONCLUSIONS}

\section{Implications for practice}

Our review has identified limited evidence from three single centre randomised controlled trials to support lymphaticovenular anastomosis for the prevention (two studies) and vascularised lymph node transfer for the treatment (one study) of breast cancer treatment-related lymphoedema of the arm. Although there is currently not enough evidence to support the widespread adoption of lymphaticovenular anastomosis or vascularised lymph 
node transfer techniques, our review has shown that when these techniques are applied by well-trained surgeons who are expert in its use, there is potential to make a real impact in outcomes for breast cancer patients.

\section{Implications for research}

Our review has highlighted major shortcomings in the present landscape of lymphoedema research. Given the dedication and time required for traditional methods for managing breast cancer treatment-related lymphoedema to be effective, there is currently not enough high-quality research assessing the effectiveness of surgical techniques. Not only has this review highlighted the potential for these techniques to prevent and treat lymphoedema after breast cancer treatment, they also have not fully investigated the potential to 'cure' lymphoedema, which would obviate the need for lifelong conservative management measures.

Well-designed, high-quality randomised controlled trials are needed. They should compare the effectiveness of surgical interventions against each other and against current gold-standard non-surgical measures. They should investigate the effectiveness of these interventions in both the prevention and treatment of lymphoedema after breast cancer treatment. These will help define the most appropriate intervention for each stage or severity of lymphoedema, providing the basis for the formulation of evidencebased guidelines. Moreover, the use of patient-reported outcome measures by the Dionyssiou study should be readily adopted and expanded upon. Indeed, the first step towards making this possible is patient and multidisciplinary involvement in the design, conduct, and analysis of randomised controlled trials to ensure that the study designs answer the questions that are important to patients.

\section{ACK N O WLEDGEMENTS}

The authors would like to thank the Cochrane Breast Cancer Group for their support throughout the review process. 


\section{RE F E R E N C E S}

\section{References to studies included in this review}

Boccardo 2009 \{published data only\}

Boccardo FM, Ansaldi F, Bellini C, Accogli S, Taddei G, Murdaca $\mathrm{G}$, et al. Prospective evaluation of a prevention protocol for lymphedema following surgery for breast cancer. Lymphology 2009;42(1):1-9.

\section{Boccardo 2011 \{published data only\}}

Boccardo FM, Casabona F, Friedman D, Puglisi M, DeCian F, Ansaldi $F$, et al. Surgical prevention of arm lymphoedema after breast cancer treatment. Annals of Surgical Oncology 2011;18(9):2500-5.

\section{Dionyssiou 2016 \{published data only\}}

Dionyssiou D, Demiri E, Tsimponis A, Sarafis A, Mpalaris V, Tatsidou G, et al. A randomized control study of treating secondary stage II breast cancer-related lymphoedema with free lymph node transfer. Breast Cancer Research and Treatment 2016;156(1):73-9.

\section{References to studies excluded from this review}

\section{Brorson \& Svensson 1998 \{published data only\}}

Brorson H, Svensson H. Liposuction combined with controlled compression therapy reduces arm lymphedema more effectively than controlled compression therapy alone. Plastic and Reconstructive Surgery 1998;102(4):1058-67.

\section{Brorson 1997 \{published data only\}}

Brorson H, Svensson H. Complete reduction of lymphoedema of the arm by liposuction after breast cancer. Scandinavian Journal of Plastic and Reconstructive Surgery and Hand Surgery 1997;31:137-43.

\section{Brorson 1998 \{published data only\}}

Brorson H, Svensson H, Norrgren K, Thorsson O. Liposuction reduces arm lymphedema without significant altering the already impaired lymph transport. Lymphology 1998;31:156-72.

\section{Brorson 2000 \{published data only\}}

Brorson $\mathrm{H}$. Liposuction gives complete reduction of chronic large arm lymphedema after breast cancer. Acta Oncologica 2000;39(3):407-20.

\section{Campisi 2006 \{published data only\}}

Campisi C, Davini D, Bellini C, Taddei G, Villa G, Fulcheri E, et al. Is there a role for microsurgery in the prevention of arm lymphedema secondary to breast cancer treatment?. Microsurgery 2006;26(1):70-2.

\section{Campisi 2014 \{published data only\}}

Campisi CC, Campisi CA. Microsurgery for prevention and early treatment of lymphatic disorders after nodal dissection. Vascular Surgery 2014;e:198.

Ciudad 2017 \{published data only\}

Ciudad P, Manrique OJ, Dat S, Sacak B, Chang WL, Kiranantawat $\mathrm{K}$, et al. A head-to-head comparison among donor site morbidity after vascularized lymph node transfer: pearls and pitfalls of a 6-year single center experience. Journal of Surgical Oncology 2017;115:37-42.

Hou 2008 \{published data only\}

Hou C, Wu X, Jin X. Autologous bone marrow stromal cells transplantation for the treatment of secondary arm lymphedema: a prospective controlled study in patients with breast cancer related lymphedema. Japanese Journal of Clinical Oncology 2008;38(10):670-4.

Maldonado 2011 \{published data only\} Maldonado GE, Pérez CA, Covarrubias EE, Cabriales SA, Leyva LA, Pérez JC, et al. Autologous stem cells for the treatment of post-mastectomy lymphedema: a pilot study. Cytotherapy 2011;13(10):1249-55.

Saaristo 2012 \{published data only\}

Saaristo AM, Niemi TS, Viitanen TP, Tervala TV, Hartiala P, Suominen EA. Microvascular breast reconstruction and lymph node transfer for postmastectomy lymphedema patients. Annals of Surgery 2012;255:468-73.

Youssef 2010 \{published data only\}

Youssef TF. Liposuction in the treatment of post mastectomy arm edema. European Journal of Surgical Oncology 2010;36:850-1.

\section{Additional references}

Augustin 2005

Augustin M, Bross F, Földi E, Vanscheidt W, Zschocke I. Development, validation and clinical use of the FLQA-I, a disease-specific quality of life questionnaire for patients with lymphedema. Vasa 2005;34(1):31-5.

\section{Becker 2006}

Becker C, Assouad J, Riquet M, Hidden G. Postmastectomy lymphedema: long-term results following microsurgical lymph node transplantation. Annals of Surgery 2006;243(3):313-5.

\section{Brennan 1996}

Brennan MG, DePompolo RW, Garden FH. Focused review: postmastectomy lymphedema. Archives of Physical Medicine and Rehabilitation 1996;77(3 Suppl):S74-80.

\section{Brorson 2002}

Brorson $\mathrm{H}$. Liposuction in arm lymphedema treatment. Scandinavian Journal of Surgery 2002;92(4):287-95.

\section{Bulley 2013}

Bulley C, Coutts F, Blyth C, Jack W, Chetty U, Barber M, et al. Prevalence and impacts of upper limb morbidity after treatment for breast cancer: a cross-sectional study of lymphedema and function. Cancer and Oncology Research 2013;1(2):30-9. 


\section{Campisi 2004}

Campisi C, Boccardo F. Microsurgical techniques for lymphedema treatment: derivative lymphatic-venous microsurgery. World Journal of Surgery 2004;28(6):609-13.

\section{Campisi 2010}

Campisi C, Bellini C, Campisi C, Accogli S, Bonioli E, Boccardo F. Microsurgery for lymphedema: clinical research and long-term results. Microsurgery 2010;30(4):256-60.

\section{Carl 2017}

Carl HH, Walia G, Bello R, Clarke-Pearson E, Hassanein AH, Cho $B$, et al. Systematic review of the surgical treatment of extremity lymphedema. Journal of Reconstructive Microsurgery 2017;33(6):412-25.

\section{Cormier 2012}

Cormier JN, Rourke L, Crosby M, Chang D, Armer J. The surgical treatment of lymphedema: a systematic review of the contemporary literature (2004-2010). Annals of Surgical Oncology 2012;19(2):642-51.

\section{Damstra 2009}

Damstra RJ, Voesten HG, Klinkert P, Brorson H. Circumferential suction-assisted lipectomy for lymphoedema after surgery for breast cancer. British Journal of Surgery 2009;96(8):859-64.

\section{Doscher 2012}

Doscher ME, Herman S, Garfein ES. Surgical management of inoperable lymphedema: the re-emergence of abandoned techniques. Journal of the American College of Surgeons 2012;215(2):278-83.

\section{Globocan 2012}

Ferlay J, Soerjomataram I, Ervik M, Forman D, Bray F, Dikshit R, et al. GLOBOCAN 2012, Cancer Incidence and Mortality Worldwide. globocan.iarc.fr (accessed prior to 26 January 2019).

\section{Hayes 2008}

Hayes SC, Janda M, Cornish B, Battistutta D, Newman B. Lymphedema after breast cancer: incidence, risk factors, and effect on upper body function. Journal of Clinical Oncology 2008;26(21):3536-42.

\section{Higgins 2002}

Higgins J, Thompson S. Quantifying heterogeneity in a metaanalysis. Statistics in Medicine 2002;21(11):1539-58.

\section{Higgins 2011}

Higgins J, Altman D, Gotzsche P, Juni P, Moher D, Oxman A, et al. The Cochrane Collaboration's tool for assessing risk of bias in randomised trials. BMJ 2011;343:d5928.

\section{Hollis 1999}

Hollis S, Campbell F. What is meant by intention to treat analysis? Survey of published randomised controlled trials. BMJ 1999;319:670-4.

\section{ISL 2009}

International Society of Lymphology. The diagnosis and treatment of peripheral lymphoedema. Lymphology 2009;45:51-60.

\section{Keeley 2010}

Keeley V, Crooks S, Locke J, Veigas D, Riches K, Hilliam R. A quality of life measure for limb lymphoedema (LYMQOL). Journal of Lymphoedema 2010;5(1):26-37.

\section{Launois 2002}

Launois R, Mègnigbêto AC, Pocquet K, Alliot F. A specific quality of life scale in upper limb lymphedema: the ULL-27 questionnaire. Lymphology 2002;35 (Suppl)(1-760):181-7.

\section{Lee 2011}

Lee B, Laredo J, Neville R. Current status of lymphatic reconstruction surgery for chronic lymphoedema: it is still an uphill battle!. International Journal of Angiology 2011;20:73-80.

\section{Leung 2015}

Leung N, Furniss D, Giele H. Modern surgical management of breast cancer therapy related upper limb and breast lymphoedema. Maturitas 2015;80(4):384-390.

\section{McLaughlin 2008}

McLaughlin SA, Wright MJ, Morris KT, Sampson MR, Brockway JP, Hurley KE, et al. Prevalence of lymphoedema in women with breast cancer 5 years after sentinel lymph node biopsy or axillary dissection: patient perceptions and precautionary behaviours. Journal of Clinical Oncology 2008;26(32):5220-6.

\section{Nagase 2005}

Nagase T, Gonda K, Inoue K, Higashino T, Fukuda N, Gorai K, et al. Treatment of lymphoedema with lymphaticovenular anastomoses. International Journal of Clinical Oncology 2005;10(5):304-10.

\section{Penha 2013}

Penha TRL, ljsbrandy C, Hendrix NAM, Heuts EM, Voogd AC, Von Meyenfeldt MF, et al. Microsurgical techniques for the treatment of breast cancer-related lymphedema: a systematic review. Journal of Reconstructive Microsurgery 2013;29(2):99-106

\section{Petrek 1998}

Petrek JA, Heelan MC. Incidence of breast carcinoma-related lymphedema. Cancer 1998;83(12 Suppl):2776-81.

\section{Preston 2008}

Preston NJ, Seers K, Mortimer PS. Physical therapies for reducing and controlling lymphoedema of the limbs. Cochrane Database of Systematic Reviews 2004, Issue 4. [DOI: 10.1002/14651858.CD003141.pub2]

\section{RevMan 2012 [Computer program]}

The Nordic Cochrane Centre, The Cochrane Collaboration. Review Manager (RevMan). Version 5.2. Copenhagen: The Nordic Cochrane Centre, The Cochrane Collaboration, 2012. 


\section{Rockson 2008}

Rockson SG. Diagnosis and management of lymphatic vascular disease. Journal of the American College of Cardiology 2008;52(10):799-806.

\section{Scaglioni 2017}

Scaglioni MF, Arvanitakis M. Systematic review of lymphovenous anastomosis (LVA) for the treatment of lymphedema. Microsurgery 2017;37(8):947-53.

\section{Shih 2009}

Shih YC, Xu Y, Cormier JN, Giordano S, Ridner SH, Buchholz TA, et al. Incidence, treatment costs, and complications of lymphoedema after breast cancer among women of working age: a 2-year follow-up study. Journal of Clinical Oncology 2009;27(12):2007-14.

\section{Stuiver 2012}

Stuiver MM, Ten Tusscher MR, Agasi-Idenburg CS, Lucas C, Aaronson NK, Bossuyt PMM. Conventional interventions for preventing clinically detectable upper-limb lymphoedema

\section{CHARACTERISTICS OF STUDIES}

Characteristics of included studies [ordered by study ID] in patients who are at risk of developing lymphoedema after breast cancer therapy. Cochrane Database of Systematic Reviews 2012, Issue 4. [DOI: 10.1002/14651858.CD009765]

\section{Vignes 2002}

Vignes S, Trévidic P. Role of surgery in the treatment of lymphedema [Place de la chirurgie dans le traitement des lymphœdèmes]. La Revue de Médecine Interne 2002;23(Suppl 3):426-30s.

\section{Yamamoto 2011}

Yamamoto T, Yamamoto N, Doi K, Oshima A, Yoshimatsu H, Todokoro T, et al. Indocyanine green-enhanced lymphography for upper extremity lymphedema: a novel severity staging system using dermal backflow patterns. Plastic and Reconstructive Surgery 2011;128(4):941-7.

\section{Yamamoto 2013}

Yamamoto T, Yamamoto N, Hara H, Mihara M, Narushima M, Koshima I. Upper extremity lymphedema index: a simple method for severity evaluation of upper extremity lymphedema. Annals of Plastic Surgery 2013;70(1):47-9.

Boccardo 2009

\begin{tabular}{|c|c|}
\hline Methods & Single centre randomised controlled trial \\
\hline Participants & $\begin{array}{l}55 \text { women scheduled to undergo breast conserving surgery or radical mastectomy and axillary clear- } \\
\text { ance for breast cancer. } 6 \text { women dropped out after randomisation. Intervention group: } n=25 \text {. Compar- } \\
\text { ison group: } n=24 \text {. Age of participants } 54.07 \pm 10.54 \text { (mean } \pm S D \text { ). }\end{array}$ \\
\hline \multirow[t]{2}{*}{ Interventions } & $\begin{array}{l}\text { Intervention: lymphaticovenular anastomosis was performed to prevent lymphoedema formation ei- } \\
\text { ther during primary operation if lymphatic impairment was identified in preoperative lymphoscintigra- } \\
\text { phy or later if physical treatment failed in preventing lymphoedema development and lymphoscintig- } \\
\text { raphy done at } 6 \text { months revealed impairment in lymph flow. }\end{array}$ \\
\hline & Comparator: no preventive strategies were used. \\
\hline
\end{tabular}

Outcomes Lymphoedema was defined as arm volume increase of $200 \mathrm{~mL}$ from baseline.

Percentage of arm volume increase was also reported.

Reported at 1, 3, 6, 12, and 24 months.

Notes Setting: S.Martino Hospital, Genoa, Italy

\section{Risk of bias}

\begin{tabular}{lll}
\hline Bias & Authors' judgement & Support for judgement \\
\hline $\begin{array}{l}\text { Random sequence genera- } \\
\text { tion (selection bias) }\end{array}$ & Unclear risk & Not stated \\
\hline $\begin{array}{l}\text { Allocation concealment } \\
\text { (selection bias) }\end{array}$ & Unclear risk & Not stated \\
\hline
\end{tabular}


Boccardo 2009 (Continued)

Blinding of participants High risk Unable to blind either surgeons or participants and personnel (performance bias)

All outcomes

\section{Blinding of outcome as- High risk} sessment (detection bias)

All outcomes

\section{Incomplete outcome data Unclear risk}

(attrition bias)

All outcomes

\begin{tabular}{lll}
\hline $\begin{array}{l}\text { Selective reporting (re- } \\
\text { porting bias) }\end{array}$ & Low risk & Outcomes reported as described in methods section \\
\hline Other bias & Low risk & Study appeared to be free of other sources of bias \\
\hline
\end{tabular}

Regardless of who assessed outcomes, it would be very difficult to blind outcome assessment because of participant's knowledge and the presence of surgical scars.

$89 \%$ of participants were assessed at 2 years. 6 participants did not finish follow-up to 24 months. No reasons mentioned

Boccardo 2011

\begin{tabular}{ll}
\hline Methods & Single centre randomised controlled trial \\
\hline Participants & $\begin{array}{l}46 \text { women scheduled to undergo complete axillary dissection. Average age 57 years (range 39-80). In- } \\
\text { tervention group: } \mathrm{n}=23 . \text { Comparison group: } \mathrm{n}=23\end{array}$ \\
\hline Interventions & $\begin{array}{l}\text { Intervention: lymphaticovenular anastomosis was performed at the time of axillary dissection. } \\
\text { Comparator: local standard practice was followed in the comparison group. } \\
\text { Lymphocintigraphy was performed pre- and postoperatively to demonstrate patency of the lymphat- } \\
\text { ic-venous anastomosis. }\end{array}$
\end{tabular}

\begin{tabular}{ll}
\hline Outcomes & $\begin{array}{l}\text { Lymphoedema was defined as arm volume increase of } 100 \mathrm{~mL} \text { from preoperative. } \\
\text { Reported at } 1,3,6,12 \text {, and } 18 \text { months. }\end{array}$ \\
\hline Notes & Setting: S.Martino Hospital, Genoa, Italy
\end{tabular}

\section{Risk of bias}

\begin{tabular}{lll}
\hline Bias & Authors' judgement & Support for judgement \\
\hline $\begin{array}{l}\text { Random sequence genera- } \\
\text { tion (selection bias) }\end{array}$ & Unclear risk & Not stated \\
\hline $\begin{array}{l}\text { Allocation concealment } \\
\text { (selection bias) }\end{array}$ & Unclear risk & Not stated \\
\hline $\begin{array}{l}\text { Blinding of participants } \\
\text { and personnel (perfor- } \\
\text { mance bias) }\end{array}$ & Unclear risk & Unable to blind surgeon \\
$\begin{array}{l}\text { All outcomes } \\
\text { Blinding of outcome as- } \\
\text { sessment (detection bias) } \\
\text { All outcomes }\end{array}$ & Unclear risk & $\begin{array}{l}\text { It was unclear who assessed outcomes, but participants in both groups would } \\
\text { have had identical surgical scars. }\end{array}$ \\
\hline
\end{tabular}


Boccardo 2011 (Continued)
Incomplete outcome data
Low risk
No participants lost to follow-up, no withdrawals
(attrition bias)

All outcomes

\begin{tabular}{lll}
\hline $\begin{array}{l}\text { Selective reporting (re- } \\
\text { porting bias) }\end{array}$ & Low risk & Outcomes reported as described in methods section \\
\hline Other bias & Low risk & Study appeared to be free of other sources of bias \\
\hline
\end{tabular}

Dionyssiou 2016

\begin{tabular}{ll}
\hline Methods & Single centre randomised controlled trial \\
\hline Participants & 36 women with unilateral breast cancer-related stage II lymphoedema. Intervention group: $\mathrm{n}=18$, age \\
& 47.7 years $(32-77)$ (mean (range)). Comparison group: $\mathrm{n}=18$, age 49.1 years $(30-71)$
\end{tabular}

Interventions

Intervention: vascularised lymph node transfer flap was performed from lower abdominal and upper groin region to axilla. This was followed by 6 months of physiotherapy including manual lymphatic drainage for the first month (daily for two weeks and twice per week for the following two weeks) and pressure garments worn day and night for the next 5 months. In addition, participants were instructed to apply gentle pumping pressure onto the flap to empty the excess fluid $4 \times 10$ times daily for the first 3 months.

Comparator: received the same nonoperative treatments as the intervention group for a total of 6 months only.

Outcomes Lymphoedema was defined as the difference in volume compared to the unaffected arm and reported
as volume reduction percentage.

Secondary outcomes were all reported as changes on subjectively assigned 1-10 scale assessing pain, heaviness, and overall function.

Infection rate was also reported.

Reported at 12 months after the intervention ended.

Notes Setting: Papageorgiou Hospital, Thessaloniki, Greece

\section{Risk of bias}

\begin{tabular}{lll}
\hline Bias & Authors' judgement & Support for judgement \\
\hline $\begin{array}{l}\text { Random sequence genera- } \\
\text { tion (selection bias) }\end{array}$ & Low risk & Random number generator \\
\hline $\begin{array}{l}\text { Allocation concealment } \\
\text { (selection bias) }\end{array}$ & Low risk & $\begin{array}{l}\text { "All the patients were examined thoroughly and recruited before their alloca- } \\
\text { tion into a group". This suggests allocation concealed until after assessment } \\
\text { and inclusion. }\end{array}$ \\
\hline $\begin{array}{l}\text { Blinding of participants } \\
\text { and personnel (perfor- } \\
\text { mance bias) } \\
\begin{array}{l}\text { All outcomes } \\
\text { nagh risk }\end{array}\end{array}$ & $\begin{array}{l}\text { Could not blind participants to surgical treatment. Blinding of personnel not } \\
\text { discussed }\end{array}$ \\
\hline
\end{tabular}


Dionyssiou 2016 (Continued)

Blinding of outcome as- High risk Regardless of who assessed outcomes, it would be very difficult to blind outsessment (detection bias) come assessment because of participant's knowledge and the presence of surAll outcomes gical scars.

Incomplete outcome data Low risk No participants lost to follow-up, no withdrawals
(attrition bias)

(attrition bias)

All outcomes

Selective reporting (re- Low risk Outcomes reported as described in the methods section
porting bias)

Other bias Low risk Study appeared to be free of other sources of bias

Characteristics of excluded studies [ordered by study ID]

\begin{tabular}{|c|c|}
\hline Study & Reason for exclusion \\
\hline Brorson \& Svensson 1998 & Not an RCT \\
\hline Brorson 1997 & Not an RCT \\
\hline Brorson 1998 & Not an RCT \\
\hline Brorson 2000 & Not an RCT \\
\hline Campisi 2006 & Unclear whether an RCT. No response from authors \\
\hline Campisi 2014 & $\begin{array}{l}\text { Abstract at a conference. Unclear whether results overlapped with another included study (Boccar- } \\
\text { do 2011). Incomplete details for methods used as full article of study was not published. }\end{array}$ \\
\hline Ciudad 2017 & Not an RCT \\
\hline Hou 2008 & Not a surgical intervention \\
\hline Maldonado 2011 & Not an RCT \\
\hline Saaristo 2012 & Not an RCT \\
\hline Youssef 2010 & $\begin{array}{l}\text { Poster abstract at a conference. Unclear whether an RCT (unlikely). Data not published elsewhere. } \\
\text { No contact details found. }\end{array}$ \\
\hline
\end{tabular}

DATA AND ANALYSES

Comparison 1. Prevention of LE

\begin{tabular}{lllll}
\hline Outcome or subgroup title & No. of studies & $\begin{array}{l}\text { No. of partici- } \\
\text { pants }\end{array}$ & Statistical method & Effect size \\
\hline 1 Development of LE & 2 & 95 & Risk Ratio (M-H, Fixed, 95\% Cl) & $0.20[0.06,0.63]$ \\
\hline
\end{tabular}


Analysis 1.1. Comparison 1 Prevention of LE, Outcome 1 Development of LE.

\begin{tabular}{|c|c|c|c|c|c|}
\hline \multirow[t]{2}{*}{ Study or subgroup } & \multirow{2}{*}{$\begin{array}{l}\text { LVA } \\
\mathrm{n} / \mathrm{N}\end{array}$} & \multirow{2}{*}{$\begin{array}{c}\text { Standard } \\
\text { practice } \\
n / N\end{array}$} & \multirow{2}{*}{$\begin{array}{c}\text { Risk Ratio } \\
\text { M-H, Fixed, } 95 \% \mathrm{Cl}\end{array}$} & \multirow[t]{2}{*}{ Weight } & \multirow{2}{*}{$\begin{array}{c}\text { Risk Ratio } \\
\text { M-H, Fixed, 95\% Cl }\end{array}$} \\
\hline & & & & & \\
\hline Boccardo 2009 & $2 / 25$ & $8 / 24$ & -1 & $53.84 \%$ & $0.24[0.06,1.02]$ \\
\hline Boccardo 2011 & $1 / 23$ & $7 / 23$ & [ & $46.16 \%$ & $0.14[0.02,1.07]$ \\
\hline Total $(95 \% \mathrm{Cl})$ & 48 & 47 & & $100 \%$ & $0.2[0.06,0.63]$ \\
\hline \multicolumn{6}{|c|}{ Total events: 3 (LVA), 15 (Standard practice) } \\
\hline \multicolumn{6}{|c|}{ Heterogeneity: Tau $^{2}=0 ; \mathrm{Chi}^{2}=0.17, \mathrm{df}=1(\mathrm{P}=0.68) ; \mathrm{I}^{2}=0 \%$} \\
\hline \multicolumn{6}{|c|}{ Test for overall effect: $Z=2.73(P=0.01)$} \\
\hline
\end{tabular}

\section{Comparison 2. Treatment of LE}

\begin{tabular}{llllll}
\hline Outcome or subgroup title & No. of studies & $\begin{array}{l}\text { No. of partici- } \\
\text { pants }\end{array}$ & Statistical method & Effect size \\
\hline 1 Reduction of LE & 1 & 36 & Mean Difference (IV, Fixed, 95\% Cl) & $-39.0[-47.37,-30.63]$ \\
\hline 2 Pain score (1-10 scale) & 1 & 36 & Mean Difference (IV, Fixed, 95\% CI) & $-4.16[-5.17,-3.15]$ \\
\hline $\begin{array}{l}\text { 3 Heaviness sensation score } \\
\text { (1-10 scale) }\end{array}$ & 1 & 36 & Mean Difference (IV, Fixed, 95\% Cl) & $-4.27[-5.74,-2.80]$ \\
\hline $\begin{array}{l}\text { 4 Function score (1-10 scale) } \\
\text { 5 Number of infections per }\end{array}$ & 1 & 36 & Mean Difference (IV, Fixed, 95\% Cl) & $-3.77[-4.89,-2.65]$ \\
\hline year & 1 & 36 & Mean Difference (IV, Fixed, 95\% CI) & $-1.22[0.00,-0.44]$ \\
\hline
\end{tabular}

Analysis 2.1. Comparison 2 Treatment of LE, Outcome 1 Reduction of LE.

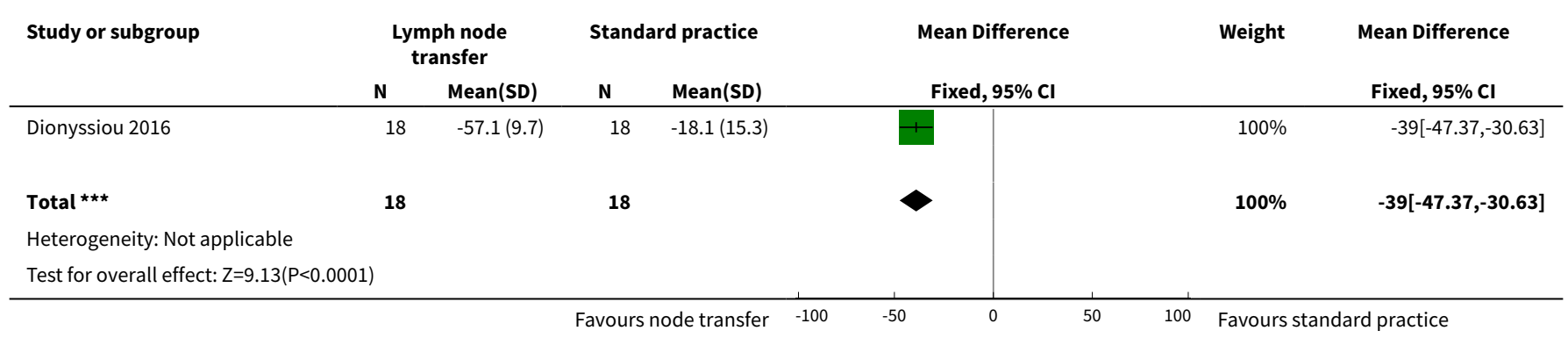


Analysis 2.2. Comparison 2 Treatment of LE, Outcome 2 Pain score (1-10 scale).

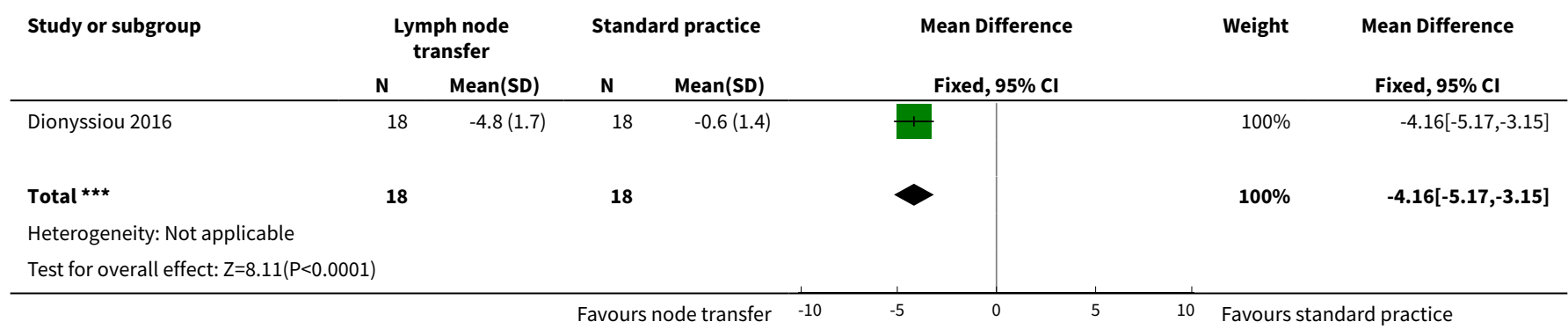

Analysis 2.3. Comparison 2 Treatment of LE, Outcome 3 Heaviness sensation score (1-10 scale).

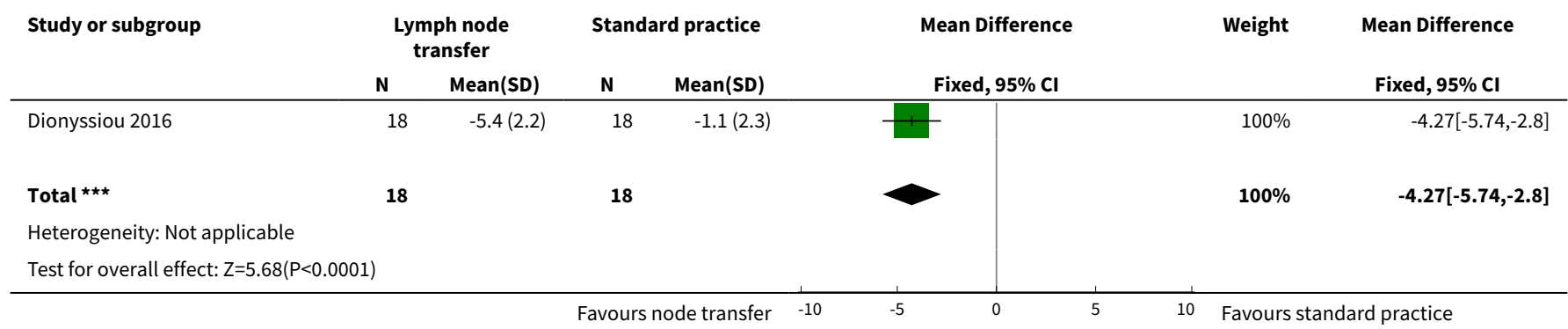

Analysis 2.4. Comparison 2 Treatment of LE, Outcome 4 Function score (1-10 scale).

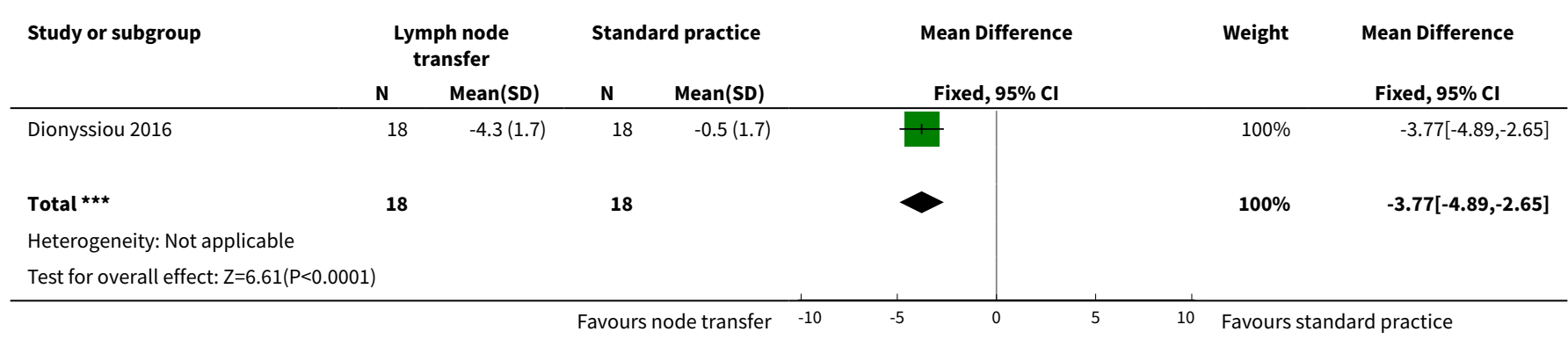

Analysis 2.5. Comparison 2 Treatment of LE, Outcome 5 Number of infections per year.

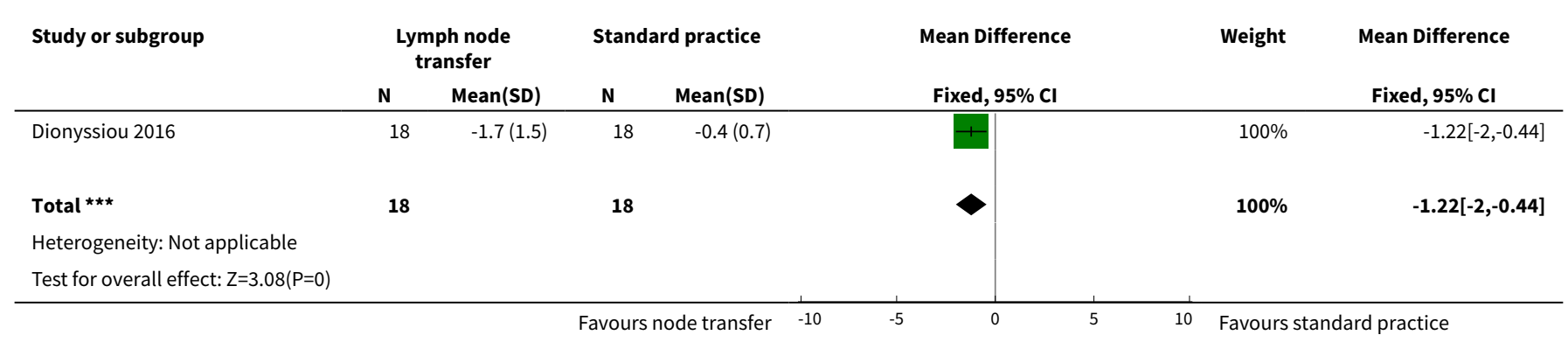




\section{APPENDICES}

\section{Appendix 1. CENTRAL}

1. MeSH descriptor: [Breast Neoplasms] explode all trees

2. breast near cancer ${ }^{\star}$

3. breast near neoplasm*

4. breast near carcinoma*

5. breast near tumour*

6. breast near tumor*

7. \#1 or \#2 or \#3 or \#4 or \#5 or \#6

8. MeSH descriptor: [Lymphedema] explode all trees

9. lymphoedema or lymphedema

10.breast cancer associated lymphoedema

11.breast cancer near/5 (lymphoedema or lymphedema)

12.\#9 or \#10 or \#11

13.MeSH descriptor: [Lipectomy] explode all trees

14.liposuction

15.lymph node transfer

16.lymph node near/5 transfer

17.MeSH descriptor: [Anastomosis, Surgical] explode all trees

18.lymphaticovenular anastomosis

19. LVA

20.Lympathico-lymphatic bypass

21.Lympathico-lymphatic near/5 bypass

22.microsurgical lymphatic reconstruction

23.lymphatic near/5 reconstruction

24. microsurgical near/5 lymphatic reconstruction

25. microsurgical near/5 lymphatic

26. Anastamotic reconstruction or Anastomotic reconstruction

27.surg* prevent* near/5 (lymphoedema or lymphedema)

28.surg ${ }^{\star}$ treat ${ }^{\star}$ near/5 (lymphoedema or lymphedema)

29.\#8 or \#9 or \#10 or \#11 or \#12 or \#13 or \#14 or \#15 or \#16 or \#17 or \#18 or \#19 or \#20 or \#21 or \#22 or \#23 or \#24 or \#25 or \#26 or \#27 or \#28 30.\#7 and \#12 and \#29

\section{Appendix 2. MEDLINE}

\begin{tabular}{ll}
\hline 1 & randomized controlled trial.pt. \\
\hline 2 & controlled clinical trial.pt. \\
\hline 3 & randomized.ab. \\
\hline 4 & placebo.ab. \\
\hline 5 & clinical trials as topic.sh. \\
\hline 6 & randomly.ab. \\
\hline 8 & trial.ab. \\
\hline
\end{tabular}

Surgical interventions for the prevention or treatment of lymphoedema after breast cancer treatment (Review)

Copyright (c) 2019 The Cochrane Collaboration. Published by John Wiley \& Sons, Ltd. 


\begin{tabular}{|c|c|}
\hline 10 & exp Breast Neoplasms/ \\
\hline 11 & (breast adj6 cancer\$).mp. \\
\hline 12 & (breast adj6 neoplasm\$).mp. \\
\hline 13 & (breast adj6 carcinoma\$).mp. \\
\hline 14 & (breast adj6 tumour\$).mp. \\
\hline 15 & (breast adj6 tumor\$).mp. \\
\hline 16 & 10 or 11 or 12 or 13 or 14 or 15 \\
\hline 17 & exp Lymphedema/ \\
\hline 18 & lymphedema.mp. OR upper-limb lymphedema.mp \\
\hline 19 & lymphoedema.mp. OR upper-limb lymphoedema.mp \\
\hline 20 & breast cancer associated lymphoedema.mp. \\
\hline 21 & breast cancer associated lymphedema.mp. \\
\hline 22 & (breast cancer adj6 (lymphoedema or lymphedema)).mp. \\
\hline 23 & 17 or 18 or 19 or 20 or 21 or 22 \\
\hline 24 & exp Lipectomy/ \\
\hline 25 & liposuction.mp. \\
\hline 26 & lymph node transfer.mp. \\
\hline 27 & (lymph node adj5 transfer).mp. \\
\hline 28 & exp Anastomosis, Surgical/ \\
\hline 29 & (lymphaticovenular anastomosis OR lymphaticovenous anastomosis).mp \\
\hline 30 & (LVA OR LYMPHA).mp \\
\hline 31 & $\begin{array}{l}\text { (Lympathico-lymphatic bypass OR axillary clearance OR axillary dissection OR axillary lym- } \\
\text { phadenectomy OR lymph node flap).mp }\end{array}$ \\
\hline 32 & (Lympathico-lymphatic adj5 bypass).mp. \\
\hline 33 & microsurgical lymphatic reconstruction.mp. \\
\hline 34 & (lymphatic adj5 reconstruction).mp. \\
\hline 35 & (microsurgical adj5 lymphatic reconstruction).mp. \\
\hline 36 & (microsurgical adj5 lymphatic).mp. \\
\hline
\end{tabular}


37 (Anastamotic reconstruction or Anastomotic reconstruction).mp.

38 (surg* prevent $^{\star}$ adj5 (lymphoedema or lymphedema)).mp.

39 (surg ${ }^{\star}$ treat $^{\star}$ adj5 (lymphoedema or lymphedema)).mp.

$40 \quad 24$ or 25 or 26 or 27 or 28 or 29 or 30 or 31 or 32 or 33 or 34 or 35 or 36 or 37 or 38 or 39

\begin{tabular}{ll}
\hline 41 & 9 and 16 and 23 and 40 \\
\hline 42 & Animals/not Humans/ \\
\hline 43 & 41 not 42
\end{tabular}

\section{Appendix 3. Embase}

\section{Search via Embase.com (2015)}

1. 'randomized controlled trial'/syn OR randomi* NEXT/10 controlled OR 'randomization'/syn OR 'random allocation' OR 'double blind procedure'/syn OR (single OR double OR tripl* OR trebl*) NEXT/1 (blind* OR mask*) OR 'clinical trial'/syn OR 'clinical trials' OR'multicenter study'/syn OR (multicentre OR multicenter) NEXT/1 stud ${ }^{\star}$ OR randomly:ab,ti OR trial:ab,ti OR groups:ab,ti

2. 'breast'/exp OR 'breast disease'/exp AND 'neoplasm'/exp OR 'breast tumor'/exp OR (breast* NEAR/5 neoplas*):ab,ti OR (breast* NEAR/5cancer ${ }^{\star}$ ):ab,ti OR (breast* NEAR/5 carcin $^{\star}$ ):ab,ti OR (breast* NEAR/5 tumo*):ab,ti OR (breast* NEAR/5 metasta*):ab,ti OR (breast ${ }^{\star}$ NEAR/5malig*):ab,ti

3. 'lymphoedema'/exp OR lymphoedema OR 'upper-limb lymphoedema'

4. 'lymphedema'/exp OR lymphedema OR 'upper-limb lymphedema'

5. 'breast cancer associated lymphoedema'

6. 'breast cancer associated lymphedema'

7. 'breast cancer' NEAR/5 (lymphoedema OR lymphedema)

8. \#3 OR \#4 OR \#5 OR \#6 OR \#7

9. 'lipectomy'/exp OR lipectomy

10.'liposuction'/exp OR liposuction

11.'lymph node transfer'

12.' 'lymph node' NEAR/5 transfer

13.Iva OR lympha

14. 'lymphaticovenular anastomosis' OR 'lymphaticovenous anastomosis'

15. 'lympathico-lymphatic bypass' OR 'axillary clearance' OR 'axillary dissection' OR 'axillary lymphadenectomy' OR 'lymph node flap'

16.' 'lympathico-lymphatic' NEAR/5 bypass

17.'microsurgical lymphatic reconstruction'

18.lymphatic NEAR/5 reconstruction

19. microsurgical NEAR/5 'lymphatic reconstruction'

20.microsurgical NEAR/5 lymphatic

21.'anastamotic reconstruction'

22.'anastomotic reconstruction'

23.'surgical prevention' NEAR/5 (lymphoedema OR lymphedema)

24. 'surgical treatment' NEAR/5 (lymphoedema OR lymphedema)

25.' 'surgical treatments' NEAR/5 (lymphoedema OR lymphedema)

26. \#9 OR \#10 OR \#11 OR \#12 OR \#13 OR\#14 OR \#15 OR \#16 OR \#17 OR \#18 OR \#19 OR \#20 OR \#21 OR \#22 OR \#23 OR \#24 OR \#25

27.\#1 AND \#2 AND \#8 AND \#26

28.\#27 NOT ([animals]/lim NOT [humans]/lim)

29.\#28 AND [embase]/lim

\section{Search via OvidSP (2017)}




\begin{tabular}{|c|c|}
\hline 1 & Randomized controlled trial/ \\
\hline 2 & Controlled clinical study/ \\
\hline 3 & Random\$.ti,ab. \\
\hline 4 & randomization/ \\
\hline 5 & intermethod comparison/ \\
\hline 6 & placebo.ti,ab. \\
\hline 7 & (compare or compared or comparison).ti. \\
\hline 8 & (open adj label).ti,ab. \\
\hline 9 & ((double or single or doubly or singly) adj (blind or blinded or blindly)).ti,ab. \\
\hline 10 & double blind procedure/ \\
\hline 11 & parallel group $\$ 1 . t i, a b$. \\
\hline 12 & (crossover or cross over).ti,ab. \\
\hline 13 & $\begin{array}{l}\text { ((assign } \$ \text { or match or matched or allocation) adj5 (alternate or group } \$ 1 \text { or intervention } \$ 1 \text { or pa- } \\
\text { tient } \$ 1 \text { or subject } \$ 1 \text { or participant } \$ 1)) . t i, a b .\end{array}$ \\
\hline 14 & (assigned or allocated).ti,ab. \\
\hline 15 & (controlled adj7 (study or design or trial)).ti,ab. \\
\hline 16 & (volunteer or volunteers).ti,ab. \\
\hline 17 & trial.ti. \\
\hline 18 & or/1-17 \\
\hline 19 & exp breast/ \\
\hline 20 & exp breast disease/ \\
\hline 21 & (19 or 20 ) and exp neoplasm/ \\
\hline 22 & exp breast tumor/ \\
\hline 23 & exp breast cancer/ \\
\hline 24 & exp breast carcinoma/ \\
\hline 25 & (breast\$ adj5 (neoplas\$ or cancer\$ or carcin\$ or tumo $\$$ or metasta\$ or malig\$)).ti,ab. \\
\hline 26 & 21 or 22 or 23 or 24 or 25 \\
\hline 27 & exp lymphedema/ \\
\hline
\end{tabular}




\begin{tabular}{|c|c|}
\hline 29 & 27 or 28 \\
\hline 30 & exp lipectomy/ \\
\hline 31 & lipectom\$.tw. \\
\hline 32 & exp liposuction/ \\
\hline 33 & liposuction.tw. \\
\hline 34 & (lymph node adj5 transfer).tw. \\
\hline 35 & (LVA or LYMPHA).tw. \\
\hline 36 & (lymphaticovenular anastomosis or lymphaticovenous anastomosis).tw. \\
\hline 37 & exp lymphovenous anastomosis/ \\
\hline 38 & $\begin{array}{l}\text { (lympathico-lymphatic bypass or axillary clearance or axillary dissection or axillary lymphadenec- } \\
\text { tomy or lymph node flap).tw. }\end{array}$ \\
\hline 39 & (lympathico-lymphatic adj5 bypass).tw. \\
\hline 40 & (lymphatic adj5 reconstruction).tw. \\
\hline 41 & (microsurger ${ }^{\star}$ adj5 lymphatic).tw. \\
\hline 42 & anastomotic reconstruction.tw. \\
\hline 43 & anastamotic reconstruction.tw. \\
\hline 44 & (surgical prevention adj5 (lymphoedema or lymphedema)).tw. \\
\hline 45 & (surgical treatment\$ adj5 (lymphoedema or lymphedema)).tw. \\
\hline 46 & or/30-45 \\
\hline 47 & 18 and 26 and 29 and 46 \\
\hline 48 & limit 47 to $y r=" 2015$-Current" \\
\hline
\end{tabular}

\section{Appendix 4. CINAHL}

S1. (MH "Clinical Trials+")

S2. PT Clinical trial

S3. TX clinic $^{\star}$ n1 trial $^{\star}$

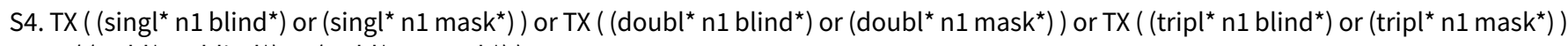
or TX ( (trebl ${ }^{\star} \mathrm{n} 1$ blind $\left.^{\star}\right)$ or (trebl* $n 1$ mask $\left.\left.^{\star}\right)\right)$

S5. TX randomi* control $^{\star}$ trial $^{*}$

S6. (MH "Random Assignment") 
S7. TX random* allocat*

S8. TX placebo*

S9. (MH "Placebos")

S10. (MH "Quantitative Studies")

S11. TX allocat* random* $^{*}$

S12. S1 OR S2 OR S3 OR S4 OR S5 OR S6 OR S7 OR S8 OR S9 OR S10 OR S11

S13. (MH "Breast Neoplasms+")

S14. TX breast cancer*

S15. TX breast tumour*

S16. TX breast tumor ${ }^{\star}$

S17. TX breast carcinoma*

S18. S12 OR S13 OR S14 OR S15 OR S16 OR S17

S19. (MH "Lymphedema+")

S20. "lymphedema" OR TX upper-limb lymphedema*

S21. "lymphoedema" OR TX upper-limb lymphoedema*

S22. TX breast cancer associated lymphoedema

S23. TX breast cancer associated lymphedema

S24. S19 OR S20 OR S21 OR S22 OR S23

S25. (MH "Lipectomy+")

S26. "liposuction"

S27. TX lymphaticovenular anastomosis

S28. "LVA" OR "LYMPHA" OR TX LVA OR TX LYMPHA

S29. TX Lympathico-lymphatic bypass

S30. TX microsurgical lymphatic reconstruction* OR TX axillary clearance OR TX axillary lymphadenectomy OR TX axillary dissection OR "axillary clearance" OR "axillary lymphadenectomy" OR "axillary clearance"

S31. TX Anastamotic reconstruction* OR TX Anastomotic reconstruction*

S32. TX (lymph node $n 5$ transfer)

S33. TX (Lympathico-lymphatic $n 5$ bypass)

S34. TX (lymphatic $n 5$ reconstruction)

S35. TX (microsurgical n5 lymphatic reconstruction ${ }^{\star}$ )

S36. TX (microsurgical n5 lymphatic)

S37. TX (surg* prevent* n5 (lymphoedema or lymphedema))

S38. TX (surg* treatment* n5 (lymphoedema or lymphedema))

S39. S25 OR S26 OR S27 OR S28 OR S29 OR S30 OR S31 OR S32 OR S 33 OR S34 OR S35 OR S36 OR S37 OR S38

S40. S12 AND S18 AND S24 AND S39

Surgical interventions for the prevention or treatment of lymphoedema after breast cancer treatment (Review) 


\section{Appendix 5. WHO ICTRP}

\section{Basic searches:}

1. Lymphoedema AND liposuction

2. Lymphoedema AND lymph node transfer

3. Lymphoedema AND lymphaticovenular anastomosis

4. Lymphoedema AND LVA

5. Lymphoedema AND Lympathico-lymphatic bypass

6. Lymphoedema AND microsurgical lymphatic reconstruction

7. Lymphoedema AND Anastomotic reconstruction

8. Lymphoedema AND Anastamotic reconstruction

9. Lymphoedema AND axillary dissection

10. Lymphoedema AND axillary lymphadenectomy

11. Lymphoedema AND axillary clearance

12. Lymphoedema AND LYMPHA

13. Lymphoedema AND lymph node flap

14. Lymphoedema AND lymphaticovenous anastomsis

\section{Advanced searches:}

\section{Condition: lymphoedema}

Intervention: liposuction OR lymph node transfer OR lymphaticovenular anastomosis OR LVA OR Lympathico-lymphatic bypass OR microsurgical lymphatic reconstruction OR Anastomotic reconstruction OR Anastamotic reconstruction OR lymphatic surgery OR lymphatic reconstruction OR surgical intervention OR lymphatic bypass OR axillary clearance OR axillary dissection OR axillary lymphadenectomy OR LYMPHA OR Lymph node flap OR lymphaticovenous anastomosis

Recruitment Status: ALL

\section{Appendix 6. ClinicalTrials.gov}

\section{5 search strategy:}

\section{Basic searches:}

1. Lymphoedema AND liposuction

2. Lymphoedema AND lymph node transfer

3. Lymphoedema AND lymphaticovenular anastomosis

4. Lymphoedema AND LVA

5. Lymphoedema AND Lympathico-lymphatic bypass

6. Lymphoedema AND microsurgical lymphatic reconstruction

7. Lymphoedema AND Anastomotic reconstruction

8. Lymphoedema AND Anastamotic reconstruction

9. Lymphoedema AND axillary dissection

10. Lymphoedema AND axillary lymphadenectomy 
11. Lymphoedema AND axillary clearance

12. Lymphoedema AND LYMPHA

13. Lymphoedema AND lymph node flap

14. Lymphoedema AND lymphaticovenous anastomsis

\section{Advanced searches:}

1. Condition: breast cancer AND lymphoedema

Intervention: liposuction OR lymph node transfer OR lymphaticovenular anastomosis OR LVA OR Lympathico-lymphatic bypass OR microsurgical lymphatic reconstruction OR Anastomotic reconstruction OR Anastamotic reconstruction OR lymphatic surgery OR lymphatic reconstruction OR surgical intervention OR lymphatic bypass OR axillary clearance OR axillary dissection OR axillary lymphadenectomy OR LYMPHA OR Lymph node flap OR lymphaticovenous anastomosis

Recruitment: All studies

Study Results: All studies

Study Type: All studies

Gender: All studies

\section{7 search strategy:}

\section{Search 1}

Condition/ Disease: breast cancer AND lymphoedema

Other terms: liposuction OR lymph node transfer OR lymphaticovenular anastomosis OR LVA OR Lympathico-lymphatic bypass OR microsurgical lymphatic reconstruction OR Anastomotic reconstruction OR Anastamotic reconstruction OR lymphatic surgery

\section{Search 2}

Condition/ Disease: breast cancer AND lymphoedema

Other terms: lymphatic reconstruction OR surgical intervention OR lymphatic bypass OR axillary clearance OR axillary dissection OR axillary lymphadenectomy OR LYMPHA OR Lymph node flap OR lymphaticovenous anastomosis

\section{WHAT'S NEW}

\begin{tabular}{lll}
\hline Date & Event & Description \\
\hline 20 February 2019 & Amended & Correction to the author's affiliation \\
\hline
\end{tabular}

\section{CONTRIBUTIONSOF AUTHORS}

Draft of the protocol: PM, NL, VA, DF

Study selection: PM, NL, VA, DF

Extraction of data from studies: PM, NL, VA, DF

Entering data in RevMan 2012: PM, NL, VA

Carrying out the analysis: PM, NL, VA, DF

Drafting the final review: $\mathrm{PM}, \mathrm{NL}, \mathrm{VA}, \mathrm{DF}$

Disagreement resolution: DF

Update of the review: PM, NL, VA, DF

\section{DECLARATIONSOF INTEREST}

None known. 


\section{SOURCES OF SUPPORT}

\section{Internal sources}

- No support provided, Other.

\section{External sources}

- No sources of support supplied

\section{DIFFERENCES BETWEEN PROTOCOLAND REVIEW}

- We modified search strategies for Embase and Clinicaltrials.gov for the 2017 search update. This was due to changes in access to Embase and a modified search interface of ClinicalTrials.gov. Details are included in the Appendices.

- We added a definition on the classification of unclear risk of bias overall in the Methods section of the review.

- We added a new subgroup - participants with different stages of lymphoedema - for consideration in future review updates.

\section{N DEX TERMS}

\section{Medical Subject Headings (MeSH)}

Anastomosis, Surgical [methods]; Arm; Breast Neoplasms [ ${ }^{\star}$ radiotherapy] [ ${ }^{*}$ surgery]; Lymphatic Vessels [radiation effects] [ ${ }^{\star}$ surgery] [transplantation]; Lymphedema [etiology] [* prevention \& control] [ ${ }^{*}$ surgery]; Postoperative Complications [* ${ }^{\star}$ prevention \& control] [ ${ }^{\star}$ surgery]; Randomized Controlled Trials as Topic; Reproducibility of Results; Venules [ ${ }^{\star}$ surgery]

\section{MeSH check words}

Female; Humans 